\title{
The Future of Internet Governance: Dystopia, Utopia, or Realpolitik?*
}

\author{
Richard Hill
}

Association for Proper Internet Governance, Switzerland

Copyright $(2018$ by authors, all rights reserved. Authors agree that this article remains permanently open access under the terms of the Creative Commons Attribution License 4.0 International License

\begin{abstract}
The first discussions regarding issues that are now included under the rubric "Internet governance" date back to the 1990s. Discussions were formally brought into the arena of intergovernmental discussions in 1998, at the Plenipotentiary Conference of the International Telecommunication Union (ITU) and continued in particular at the World Summit on the Information Society (WSIS) in 2005. Discussions have tended to be difficult, and little consensus has been reached, regarding a number of issues. The factors that make discussions difficult are financial, geopolitical, but also ideological. Some of the ideological approaches are idealistic and propose governance models that are new and innovative; other approaches are conservative and propose either to continue unchanged the current Internet governance arrangements, or to apply traditional intergovernmental mechanisms to at least some aspects of Internet governance. This paper concludes that an agreed international framework is needed in order to ensure that Internet governance can evolve to meet the interests of all concerned parties.
\end{abstract}

Keywords Internet Governance, Multi-stakeholder Models

\section{Introduction}

Communications in general, and telecommunications in particular, have always been understood to be important factors in facilitating economic, political, and military activities, including economic imperialism [1, 2, 3 Chapter 2]. Thus, it is not surprising that states have always shown an interest in communications and telecommunications, recognizing that intervention may be needed to achieve certain outcomes (which may include ensuring competition) [4], and even providing such facilities as state services. In a remarkably prescient article Baran [5] discusses the question of whether, and if so how, interconnected computers should be considered a public utility. ${ }^{1}$ In terms of research and development, and early deployment, the Internet (see below for a definition of the term) is no exception to the propensity of states to be involved in telecommunications. Its protocols were developed by researchers funded by the US Defense Department Advanced Projects Research Agency (DARPA), and its early deployment was funded in the US first by DARPA, then by the National Science Foundation (NSF), and in Europe by various state-owned or state-funded universities [6, 7 p. 356]. Initial use of the Internet was restricted to non-commercial activities. However, by 1990 a significant number of private companies were connected to the Internet, so there was pressure to allow commercial use of the network. ${ }^{2}$ And indeed this was formalized in 1995 when the National Science Foundation ended its sponsorship of certain backbone services [6].

The growth of the commercial use of the Internet was comparable to that of other modern commercial telecommunications technologies [8], that is, very rapid, even if it has not (or at least not yet) reached as many people as mobile telephony. ${ }^{3}$ This rapid growth and the consequent importance of the Internet for economic activities have not surprisingly, led to a renewed interest by states in various matters related to or arising out of the Internet [10-14]. However there is little agreement amongst states regarding their proper role, and indeed there are even disagreements within states. Some consider that the current situation is perfectly acceptable, or at least that it should be allowed to evolve without too much government intervention. Others consider that the current situation is

\footnotetext{
1 The author was made aware of Baran's article through a citation in Morozov, Evgeny, 2013. "The Real Privacy Problem", MIT Technology Review, vol. 116 no. 6, p. 33.

2 While the Internet was the first international pervasive network used by consumers for searches and electronic commerce, it was not the first such pervasive network. The first such pervasive network was a national network, the French Minitel [9].

In 2017 , there were some 3.6 billion people connected to the Internet, versus some 7.7 billion mobile phone subscriptions (source ITU); a more detailed discussion is given in section 6 below.
} 
not satisfactory for at least certain issues, so some form of government involvement is required. At the international level, the privileged role of the United States of America with respect to certain matters has been criticized [15-18].

But, amongst those who criticize the current situation, there are differing views regarding what changes to make. As we will see, some propose solutions involving little or no government control; others propose a greater role for governments. In particular, the scope for intergovernmental involvement is the subject of sharp disagreements. Given the differences in views, discussions, were first started in the mid-1990s [19], continued formally at the intergovernmental level starting in 1998 (at the Plenipotentiary Conference of the International Telecommunication Union (ITU) ${ }^{4}$ ) and were pursued in greater depth starting in 2003 (at the World Summit on the Information Society (WSIS) [11]; they continue to this day in various forums, including the 2012 World Conference on International Telecommunications (WCIT) [20], the 2012 World Telecommunication Policy Forum (WTPF), the ITU Council Working Group on International Internet-related public policy issues (CWG-Internet), the continuing WSIS process, and no doubt future ITU Plenipotentiary Conferences.

This paper briefly introduces the background behind such discussions; then discusses the differing points of view and ideologies underpinning the discussions. It then outlines possible future scenarios.

\section{A Short History of Internet Governance}

To begin with, it is important to note that the term "the Internet" is used, in practice, to refer to very different things. At times it is used to refer to the network properly speaking, at times it is used to refer to the very broad collection of products and services that are made available using networks based on the TCP/IP protocol, and at times it is used as a paradigm for free and open communications [21]. In this paper we will use the broad definition adopted in 1995 by the US Federal Networking Council [22 footnote $\mathrm{xv}$ ]:

"the global information system that:

(i) is logically linked together by a globally unique address space based on the Internet Protocol (IP) or its subsequent extensions/follow-ons;

(ii) is able to support communications using the Transmission Control Protocol/Internet Protocol (TCP/IP) suite or its subsequent

\footnotetext{
${ }^{4}$ Resolutions 101, Internet Protocol-based networks, and 102, ITU's role with regard to international public policy issues pertaining to the Internet and the management of Internet resources, including domain names and address, were first adopted in 1998 and have been revised at each subsequent plenipotentiary.
}

extensions/follow-ons, and/ or other IP-compatible protocols; and

(iii) provides, uses or makes accessible, either publicly or privately, high level services layered on the communications and related infrastructure described herein."

As any network, the Internet requires some central coordination, in particular with respect to allocation and use of identification resources: names and address; and with respect to the protocols used. The latter type of coordination is called standardization, and it will not be discussed in any detail in this paper. The names most commonly used in the Internet are "domain names" and the addresses most commonly used are "IP addresses". These correspond, functionally, to telephone numbers (which are names) and to lesser-known telephony addresses. ${ }^{5}$ Access to naming and addressing resources is essential for telecommunications and has typically been managed by national regulatory authorities at the national level [23 considering (20)], and by the International Telecommunication Union at the international level [24], because it has been considered that it is a matter of public policy to ensure that such resources are made available to all players in an equitable manner. ${ }^{6}$

However, for the Internet, the naming and addressing resources have not been managed by national regulatory authorities ${ }^{7}$. During the early years, when the Internet was a small academic network, management of names and addresses was provided by an individual, Jon Postel, funded by the US government. As the network grew, it became apparent that the central coordination function could not be handled by a single person, and that rather more sophisticated procedures and processes would probably have to be developed and implemented to assure proper coordination [25]. Consequently, the Internet Society, and other organizations, facilitated a process that resulted in certain recommendations [19]. However, the US government unilaterally rejected those recommendations and proposed instead a different approach, which led to the creation of the Internet Corporation for Assigned Names and Numbers (ICANN) [26-29]. As Mueller [26 p. 508] puts the matter, the creation of ICANN "reflected a behind-the-scenes agreement that IANA-ISOC and their corporate allies would be the ones in control of the new organization and that a specific program acceptable to the trademark lobby,

\footnotetext{
5 The International Signalling Point Codes (ISPC) defined in Recommendation ITU-T Q.708, which is used for fixed telephony; and the International Mobile Subscriber Identification (IMSI) defined in Recommendation ITU-T E.212, which is used for mobile telephony.

${ }^{6}$ Similarly, access to radio frequency spectrum is essential for certain types of telecommunications and has typically been managed by national regulatory authorities at the national level and by the ITU at the international level.

${ }^{7}$ For example, the cited European regulation states that all elements of national numbering plans should be managed by national regulatory authorities (considering (20), article 8.2(d), article 10), but makes an exception for Internet naming and addressing (considering (20)).
} 
the US Commerce Department and the Europeans would be executed."

In the approach initially proposed by the United States, its role, as a government, would have been phased out relatively rapidly. But that did not happen and the US, as a government, retained a privileged role [7 p. 356, 30]; as Powers and Jablonski [3] put the matter: "The trope of industry self-regulation was simply a ruse, placating powerful stakeholders just enough while still retaining substantial regulatory authority". Not surprisingly, this led to criticism from other governments [7, pp. 357 and 359], with explicit discussions of the matter taking place at WSIS [11]. In relation with those discussions, a working definition of Internet governance was adopted by the Working Group on Internet Governance (WGIG): "Internet governance is the development and application by Governments, the private sector and civil society, in their respective roles, of shared principles, norms, rules, decision-making procedures, and programmes that shape the evolution and use of the Internet". Discussions regarding Internet governance issues have continued ever since see the good summary in Chenou and Radu [31]. While the privatization, in 2016, of the Internet Corporation for Assigned Names and Numbers has addressed some of the issues, other issues persist [18].

\subsection{Contentious Issues}

Many issues have been the subject of discussions at both the national and international level [32 para. $13 \mathrm{ff}$ ]. A good summary, and classification, of the issues is found in [13, 33]. National authorities (governments, legislators and courts) have generally been able to find answers that are generally (but not unanimously) accepted nationally, even if certain issues (in particular related to freedom of speech and intellectual property rights) are relatively more contentious. A good discussion of the complexities of the freedom of speech issue is given by Powers and Jablonski [3 Chapter 1], who show how it has been framed in ways that favor US commercial interests. There has long been a tendency of some to consider that the Internet is, or at least should be, exempt from the laws that govern other activities. According to them, the Internet should be governed by rules that are developed by "the Internet community" through informal methods. This school of thought is referred to as "separatists" by Reidenberg [34]. As the cited author put the matter ".. the underlying fight is a profound struggle against the very right of sovereign states to establish rules for online activity."

While this struggle has consistently been resolved in favor of sovereign states and the applicability of existing laws at the national level whenever concrete cases arise [10, $35-37],{ }^{8}$ proponents of at least moderate versions of the

\footnotetext{
${ }^{8}$ There is nothing new about this. A court in New Hampshire, USA, determined in 1869 that a telegraph was a valid means to form a contract:
}

separatist approach are still active $[11,38-40],{ }^{9}$ even though the prevalent view is that conventional legal and regulatory mechanisms should be adapted as appropriate and applied to the Internet [41], as the UK put the matter: “... the internet does not exist in a different dimension and the law in the offline world should also apply in the online world". ${ }^{10}$ Indeed, a number of countries, including the UK, have adapted their offline laws to prohibit certain online behavior that is considered undesirable. ${ }^{11}$

However, at the international level, there has been considerably less agreement. Mueller [11] discusses in some depth some of the contentious issues. This paper discusses three particular issues that have been extensively discussed in formal intergovernmental forums, in particular in preparations for WSIS [32 para. 15-18, 21-22] in the ITU. They are (1) issues related to the management of Internet domain names and addresses; (2) the financial issues related to the increasing use of the Internet; (3) issues related to the relative lack of security of the Internet, including spam and lack of privacy. It is worth noting that issues (2) and (3) were identified as early as 1967 by Baran [5 p. 79 and pp. 81-73].

Much of the focus of recent discussions has been on freedom of expression and human rights. Mueller [11 p. 269] states: “... a denationalized liberalism favors a universal right to receive and impart information regardless of frontiers, and sees freedom to communicate and exchange information as fundamental and primary elements of human choice and political and social activity". Mueller even proposes mechanisms to achieve this goal. Liddicoat and Doria [45] propose a specific mechanism: “... it may be that in some situations, the technical community will not only be best placed but have the sole ability to protect human rights standards in relation to the free flow of information and ideas, precisely because they are the only community able to see the human rights issues that have been hard-wired into the very way in which the Internet operates." A similar view is expressed by Bommelaer [46], who states that " ... the Internet technical community shares a common culture that is grounded in a clear understanding of the unique technical characteristics of the Internet. These characteristics are essential to the Internet's past, present, and future success as a platform for advancing the economic and social well-being of all of its users". Analyses of the Liddicoat and Doria [45] approach, and of the unique technical characteristics of the Internet, are found in [21]. An impact of the discussions regarding human rights issues on WCIT is found in [20]. The topic of human rights will not be further discussed here.

\footnotetext{
see Howley vs. Whipple, 48 N.H. 487, 488 (1869).

9 And some technologists apparently take the view that technology should be developed that would circumvent certain government actions, in particular pervasive surveillance $[42,43]$.

${ }^{10}$ In a contribution to ITU CWG-Internet, document WG-Internet 3/3.

${ }^{11}$ In the case of the UK, see Nair and Griffin [44] who argue that a 2008

tightening of provisions regarding pornography may have been excessive.
} 


\subsubsection{Management of Internet Domain names and Addresses}

The initial discussions that led to the creation of ICANN focused on two specific issues: the lack of competition (at the time) in the domain name market and the difficulties for trademark owners to recover quickly domain names containing their trademarks. Those particular issues were addressed by ICANN immediately after it was created [28]. However, the management of Internet domain names and addresses is fundamentally different from the management of names and addresses of other telecommunication technologies in two ways: (1) it is carried out by private-sector entities and is partly carried out without any formal governmental supervision; ${ }^{12}$ (2) to the extent that there was formal governmental supervision, ${ }^{13}$ it was provided by a single country, the United States of America $([18,28,30,32$ para. 15$]$. Thus it is not surprising that there have been numerous discussions regarding these two points: should governments be more involved in the management of Internet names and addresses? If not, then why is there a special role for the USA? For a discussion of the 2015 privatization of ICANN, see [18].

\subsubsection{Financial Issues}

Starting around 1998 some developing countries expressed concern about the fact that they had (and mostly still have) to pay the full cost of connecting to the Internet, whereas in the past they received payments for connections to the telephony system [20 p. 9 ff.]. Some developing countries took the view that the financial arrangements for the Internet were inappropriate and should be changed [32 para. 15; 47]. As Powers and Jabonski [3] say: "While heavy-handed government controls over the internet should be resisted, so should a system whereby internet connectivity requires the systematic transfer of wealth from the developing world to the developed." The high cost of international Internet connectivity was recognized as an issue by WSIS (para. 27(c) of the Tunis Agenda) and led to many discussions in the ITU, but with little agreement [48]. ${ }^{14}$ Further, as described in [2, section 5] there are disagreements regarding whether the current financial arrangements for the Internet will result in sufficient returns on investment to finance the rollout of sufficient new infrastructure [49] and conversely [50]. Such discussions are by no means recent: in 1996 McKie-Mason

\footnotetext{
${ }^{12}$ For sure ICANN has a Governmental Advisory Committee (GAC), but its role is purely advisory and its representative does not have decision-making powers.

${ }_{13}$ The Internet Naming and Addressing Authority (IANA) function was carried out under a contract with the US government and an employee of the US government approved all changes to the master root zone file; the master root zone file was operated under a separate contract with the US government [30 p. 5].

${ }_{4}$ However, see Supplement 2 to Recommendation ITU-T D.50, "Reducing the Costs of International Internet Connectivity", May 2013 $<$ http://www.itu.int/rec/T-REC-D.50-201305-P!Sup2> and WTPF-2013 Opinion 1, contained in the Chairman's Report <http://www.itu.int/md/S 13-WTPF13-C-0016/en>.
}

and Varian [50] explained the economics of the Internet and why some sort of pricing method might be needed to reduce congestion and optimize investments.

Mueller [11] describes well how the financial issues that were supposed to be the focus of discussion at WSIS got sidetracked and replaced by discussions of Internet governance in general and the management of domain names and addresses in particular. Financial issues were also expected to be the focus of WCIT and indeed they played a very important role during the preparatory process for that conference [20] and resulted in an agreement to revise significantly the financial provision of the ITRs [20 pp. $104 \mathrm{ff}$.]. However, as at WSIS, financial matters were pushed into the background by discussions of other issues, in particular the relation between security and freedom of speech. While there is a relation between security and freedom of speech, this author argues that the security provisions discussed and approved at WCIT could not adversely affect human rights [20, 52].

\subsubsection{Security}

It is well known that the Internet lacks pervasive security mechanisms and that this has led to a proliferation of malware and spam [21, 32 para. 17-18, 53-55]. While there is broad agreement that security should be improved and spam should be combated [ 20 p. 77], there is no agreement on how best to do that. Some take the view that private-sector initiatives should be privileged, others take the view that government actions are also required (including in the US, see [3 Chapter 7]); but, within this latter group, there are divergent views regarding the need for formal intergovernmental agreements and regarding the forums in which discussions should take place [21 section $6,56]$. In this author's opinion, not enough attention has been given to the externality effects of security - or rather, lack of security - which effects are well explained by Schneier [57]. This situation might change in light of Microsoft's decision to stop providing security updates for Windows XP, because an exploitation of a security flow might have a large enough effect to bring the externality to public attention [58]. And indeed Microsoft has recently called for various actions to address certain issues, including a treaty under which states would agree, inter alia, to refrain from stockpiling vulnerabilities [59].

\subsubsection{Summary}

At the international level, there are strong disagreements regarding how best to address various issues that has been contentious for many years. Much of the disagreement arises because of fundamentally different ideological outlooks. This situation is explored in the next section.

\section{The Differing Ideologies}

"The Internet began with the spirit of 'hope springs 
eternal'. Today, sadly, we live in a time of cyberphobia." [54 p. 8]. Although this statement refers to cyberwar, cybercrime, and pervasive surveillance, it well captures the sentiments of most parties in the Internet governance discussions. The Internet has grown rapidly and it is undeniably an important component of modern economies. Thus it has undoubtedly been a positive force. However, as any new technology, it has engendered some economic changes and, in addition, it has had side-effects which some consider negative [21,60], for example spam (for an in-depth treatment of spam, see [55]). Apart from maintaining the status quo, the differing views regarding Internet governance could initially be characterized as: $:^{15}$

a) Promoting an idealistic view in which Internet users themselves govern the Internet.

b) Promoting a traditional view in which governments govern the Internet nationally, and coordinate through traditional intergovernmental organizations to govern it internationally.

However, during WSIS, a third paradigm emerged, and was officially sanctioned in the Tunis Agenda [11 p. 78]:

c) Promoting a view in which different interest groups are recognized as having specific roles and responsibilities.

This third paradigm is now referred to as "the multi-stakeholder model" and its virtues are extolled by its proponents. Some of those proponents go further, and take the view that all of the several stakeholders should have equal rights, that it, governments should not have any particular preeminent role [63, 64]. That paradigm is discussed in more detail below. Not surprisingly, there is no agreement in favor of any one paradigm. Depending on one's point of view, one can characterize the paradigms as utopia [65], dystopia [66], or realpolitik [67]. This is discussed in more detail below.

Idealists would like to find Internet governance arrangements that maintain lofty ideals such as freedom of speech. And indeed concrete proposals for how to achieve that have been made $[11,14]$. Realists are of the view that such proposals are utopian. Indeed, from a literal point of view, they are utopian because, as we saw earlier, governments apply national laws, including restrictions on freedom of speech, to the Internet. A good criticism of the idealistic approach is found in [68]. But in fact even the multi-stakeholder model is a utopia, because current arrangements do not correspond to any of the various definitions that have been proposed for "the multi-stakeholder model". ${ }^{16}$

\footnotetext{
${ }^{15}$ This is a simplification of debates in which various variations of the main views have been proposed. Musiani and Pohle [61] provide a more nuanced summary.

${ }_{16}$ Drake [62] does not go that far, but does present in detail some short-comings of the actual multi-stakeholder arrangements that predominate with respect to Internet governance.
}

\section{The Multi-stakeholder Model}

As discussed in [21], the Internet is the first public communication system that allows anybody to publish at low cost information that can be easily accessed anywhere in the world. This has facilitated the creation of transnational communities of people with common interests, and no one state has authority over those communities. Thus it is not surprising that the Internet has reinforced and galvanized pre-existing challenges to the power of states and it has given rise to questions regarding the transfer of certain powers to non-governmental institutions [69-71]. It has also raised questions regarding the need for states to take measures to avoid or mitigate extra-territorial effects of their actions, and to avoid or mitigate interfering with the national sovereignty of other states with respect to matters where sovereignty is retained [69 pp. 17-18].

It should also be noted that the Internet is a system in which information provided by the users is used to generate advertising revenue streams that finance services provided at no direct cost to the user (such as e-mail, search engines, and social networks) [72-76]. This might seem to be an anodyne matter of contract law: a company agrees to provide services in exchange for information, and users agree to provide information in exchange for services. But in fact such agreements affect third parties and have far-reaching (possibly unintended) effects on privacy and freedom [75, 77 pp. 2-3]. Thus they affect society as a whole, are matters of public policy, and thus a legitimate concern of governments $([75,76,77$ p. 4].

The current arrangements for Internet governance are often referred to as "the multi-stakeholder model". That model has been defined as engaging "technologists, the private sector and civil society in a bottom-up, consensus driven approach to standards setting, Internet development, and management" [78]. Note that this formulation excludes governments, but that governments are included in other formulations. ${ }^{17}$ While some consider that governments should be on an equal footing with other stakeholders, including private companies, ${ }^{18}$ others consider that, as provided in the Tunis Agenda, governments should have a special role with respect to public policy. ${ }^{19}$ In fact, many variations of multi-stakeholder models are actually used in Internet governance $[18,79,80]$. Key aspects of the

\footnotetext{
${ }^{17}$ In particular in the Tunis Agenda, but also in a contribution by the UK to the CWG-Internet, document WG-Internet $3 / 3$.

${ }^{18}$ See the comments made at the Second Meeting of the Working Group on Enhanced Cooperation, 6 November 2013

$<$ http://unctad.org/meetings/en/SessionalDocuments/WGEC 2013-11-06

Transcript en.pdf $>$ accessed 21 November 2013; in particular by Virat $\bar{B}$ hatia, speaking for business (p. 35-36; 53-54), and by Adres Piazza, member of the technical community (p. 19).

${ }^{19}$ See for example the comments by Parminder Jeet Singh made at the Second Meeting of the Working Group on Enhanced Cooperation, 6 November 2013

$<$ http://unctad.org/meetings/en/SessionalDocuments/WGEC 2013-11-06

Transcript en.pdf>, pp. 27, 34, 44 accessed 21 November 2013; and, at the same meeting, by Saudi Arabia, pp. 44-45.
} 
multi-stakeholder model are the representation of the different interest groups, and the stress on consensus, meaning that formal decision-making processes such as voting should be avoided. The idea that different interest groups should meet, as such, to discuss issues and agree solutions is of course not new: indeed it can be traced back to ancient times, and it is related to debates regarding collective versus individual rights and actions [81].

In fact, the multi-stakeholder model is related to the corporatist model of governance [82]. In the corporatist model, society (or at least some aspects of society) are organized by major interest groups on the basis of common interests [83] and even exercise public authority [84 p. 19]. This is exactly what is called for in the multi-stakeholder model of Internet governance: as already noted, some proponents of that model take the view that governments are just one more interest group. As Powers and Jablonski [3 Chapter 1] put the matter: "the discourse of multistakeholderism is used to legitimize arrangements benefiting powerful, established actors like the US and its robust ICT private sector." While the concept of multi-stakeholderism is relatively recent, the concept of the US (and other) countries using state power to favor domestic telecommunication companies is hardly new. ${ }^{20}$ As Schiller [7 p. 356] puts the matter: “... in practice ... the Internet's supposedly bottom-up decision-making processes are disproportionately responsive to U.S. preferences". It must be stressed that the multi-stakeholder model does not favour economic liberalism; on the contrary, as we will see in more detail later, it favours concentration and domination by large companies, which reduces competition and is contrary to economic liberalism.

It is worth noting that the multi-stakeholder model was not instrumental in the creation and early deployment of the Internet. Indeed the creation and early deployment were the work of academics funded initially by the US Department of Defence and later by various academic institutions [3 Chapter 3, 85]. Subsequently, commercial companies developed products and services, and provided the infrastructure allowing users to access those products and services. Thus the Internet followed the same development cycle as did other communication technologies [86]. Foster and McChesney [87] provide a good analysis of the matters outlined above. It is also worth noting that the current Internet governance arrangements don't actually conform to a pure multi-stakeholder model, because some important areas are managed by entities that

\footnotetext{
${ }^{20}$ Referring to the period after World War I, Powers and Jablonski [3, Chapter 2] say: "Where US business enjoyed preferential treatment, American policy sought to entrench the status quo; where US commercial activity was burdened, as by the British cartels, the US fought for open communications." Subsequent developments fostered a US economic empire based upon "a system of international relations that puts the United States at the center of a web of international lines of communication, public and private, from which it is intended that the US economy and favored companies shall benefit." (the quote is from [1, p. 23]).
}

are not themselves multi-stakeholder.

For example, participants in the Internet Engineering Task Force (IETF) tend to represent the interests of manufacturers and users of network equipment; participants in the Regional Internet Registries (RIRs), which manage IP addresses, tend to represent the interests of Internet service providers. Thus, those entities are not truly multi-stakeholder in terms of actual representation. Further, in some cases there appears to have been some filtering of participation in certain groups [88]; actual participation is largely limited to those who are adequately funded, speak English, and have certain technical knowledge [62, 89 p. 195,90 p. 559]; and certain subgroups (for example those dealing with security) are not particularly diverse, open or transparent [91 pp. 185-186]. Yet the actual participation, and the motivations of those who participate, is important factors that can affect the legitimacy of a participative process [92].

ICANN is truly multi-stakeholder, because the participants do represent very different interest groups [29]. But governments have different rights than other stakeholders: on the one hand because the Governmental Advisory Committee (GAC) is the only group singled out as having a special role in giving advice, on the other hand because the GAC's representative to the ICANN Board cannot vote. In this sense, governments have a lesser role in ICANN than other stakeholders. (And ICANN has, at times, ignored advice even from the US government [93].)

Mueller [94] makes the point that states operate in their own self-interest, which is not necessarily the interest of some other group such as the community of Internet users. In particular, states tend to take measures to control entities that might undermine or threaten their power. ${ }^{21}$ But Mueller's cogent comments on states apply, by analogy, to other types of entities. Private corporations will take measures to maximize profits (and such measures may not be aligned with the public interest [17], in particular with respect to security [91 p. 173]. Civil society groups will take measures that reflect the interests of their particular constituencies. And so on. Thus, each of the component entities of a multi-stakeholder governance model will attempt to obtain outcomes that meet their particular goals: higher profits for companies, more control for governments, specific ideals for civil society. Since those outcomes are contradictory, and indeed sometimes mutually exclusive, it is not surprising that little consensus is reached in multi-stakeholder discussions of Internet governance. That is, such multi-stakeholder discussions tend to perpetuate the status quo. Since the status quo favours the US, it is not surprising that the US wages a concerted campaign to maintain the multi-stakeholder model and consequently the status quo [7 p. 357].

\footnotetext{
${ }^{21}$ For example, states take measures against organizations or individuals who are thought to represent a violent threat; those measures are justified as protecting "national security" and can include pervasive surveillance [95 pp. $43,46,53 \mathrm{ff}$., $71 \mathrm{ff}$.]
} 


\subsection{Diverging Views Regarding the Multi-stakeholder Model}

Those who promote the current governance model (which they refer to as "the multi-stakeholder model") are of the view that that model has worked well so far and provides the best model for the future. As the UK put the matter "Governments need to support the existing processes and help them to adapt so that they are able to keep pace with the challenges, opportunities and technical developments of the future and to ensure that the internet continues to evolve as the critical global platform for economic growth, opportunity and social well-being.," 2 : A good overall summary of this view is given in $[96$ section 2.2(a)].

Those who criticize the current governance model point out that it is that very model that has resulted in some of the undesirable features of the Internet (such as spam) and that that model may lead to severe problems in the future, that is, to dystopia [60]. As Saudi Arabia put the matter: "Recent events ${ }^{23}$ have also underscored how inappropriate and even dangerous it is for the world to just stand by, accepting the status quo, without taking the practical steps needed to address current issues through implementing what has been agreed in WSIS. This will not be achieved unless enhanced cooperation ${ }^{24}$ is operationalized, through an intergovernmental entity under the UN system." 25 And: "There is a policy vacuum in most areas of Internet governance, highlighting the need for governments to step up and perform their full role." And: "It is important to realize the governments are the bodies who have obligations to their citizens, to protect them from harm and to establish and maintain their rights both offline and online." ${ }^{26}$ A good overall summary of this view is given in [96 section 2.2(b)].

Drake [62] analyses the imperfections of the multi-stakeholder model with respect to Internet governance and proposes some improvements. An Indian civil society organization has criticized the results of the current Internet governance model. ${ }^{27}$ Sutherland [97] points out that it is relatively easy to "pack" multi-stakeholder meetings so as to influence their outcome and that there is a lack of transparency regarding who is paying whom to participate in such meetings. More fundamentally, as Powers and Jablonski [3 Chapter 5] put

\footnotetext{
${ }^{22}$ In a contribution to CWG-Internet, document WG-Internet-3/3.

23 The reference to "recent events" was no doubt a reference to the revelations regarding the US Prism surveillance program, which is described in a number of sources, for example [102].

24 The term "enhanced cooperation" was no doubt meant as an euphemism for "reducing the dominant role of the USA".

${ }_{25}$ In a contribution to the ITU Council Working Group on international Internet-related public policy issues, document WG-Internet-3/7.

${ }^{26}$ Statement by Saudi Arabia at the Second Meeting of the Working Group on Enhanced Cooperation, 7 November 2013 http://unctad.org/meetings/en/SessionalDocuments/WGEC_2013-11-07 Transcript en.pdf $>$ p. 42, accessed 21 November 2013.

${ }^{27}$ Knowledge Commons Brazil $<$ http://www.knowledgecommons.in/bras il/?page_id=10> accessed 3 April 2014.
}

the matter: "... the United States government leverages the private sector to tilt international negotiations in its favor"; the cited authors offer "a critique of the multi-stakeholder process that too often operates as a proxy to ensure private sector voices and interests dominate international fora." And institutions such as ICANN, IETF, and ISOC "through multiple layers of governance, reflect dominant political and/or economic interests, deploying discourses of multistakeholderism to legitimize arrangements benefiting powerful, established actors like the US and its robust ICT private sector" [3 Chapter 6, 18]; regarding ISOC, Powers and Jabloknsi [3] say: "With its Board and operational leadership so closely connected to established political and corporate institutions, one may question how effectively ISOC is able to represent non-commercial, global, civil society perspectives during multistakeholder negotiations." Corwin [98] gives a detailed account of ICANN actions that were apparently initiated top-down and that were decided and conducted in a non-transparent manner (but then paradoxically goes on to defend the status quo). A group of civil society organizations has summarized various criticisms of ICANN (and proposed some solutions) [99]. A former member of the ICANN Board has formulated very sharp criticisms of ICANN. ${ }^{28}$ And even a strong proponent of the current arrangements admits (speaking of ICANN) that "it is not clear that the results of the present system are producing adequately unbiased results". ${ }^{29}$

Various proposals have been made to assign at least some aspects of Internet governance to at least some parts of the UN [96 section 2.2(c), 100, 101 p. 60], ${ }^{30}$ but those proposals have been criticized because, in the UN, only governments can make formal decisions, and, furthermore, some governments are not democratic. The first point is also a criticism of national government involvement in Internet matters, since decisions are made by national parliaments in which only elected representatives vote. That is, national decisions are not made by multi-stakeholder models; they are made by elected representatives who normally consult various interest groups before making decisions. The second point is also a criticism of some components of the multi-stakeholder model. Private companies are not democratic, and some of

\footnotetext{
${ }^{28}$ Karl Auberbach, in a posting to David Faber's Interesting People list. Essentially, Auerbach argues that ICANN has become a guild and acts in the interests of the very domain name industry that it is supposed to regulate, without taking the public interest into account $<$ http://www.listbox.com/member/archive/247/2014/03/sort/time rev/pa ge/2/entry/20:218/20140326141652:C4FBE750-B512-11E3-8A4D-F200 EA6C0A5D/> accessed 3 April 2014. He makes the same points in more detail in a letter to the US Congress $<$ http://cavebear.com/docs/ntia-icann -2014-others.pdf $>$ accessed 26 April 2014.

${ }^{29}$ Vint Cerf, in a posting to the ICANN's IANA transition mailing list $<\mathrm{http}$ ///mm.icann.org/pipermail/ianatransition/2014-April/000325.html> accessed 10 April 2014. Similar comments were made by others on ISOC mailing lists.

${ }^{30}$ See also Annex B of one of the responses to a US government request for comments:

$<$ http://www.ntia.doc.gov/legacy/ntiahome/domainname/dnstransition/co mments/dnstrans_comment0081.htm> accessed 13 June 2013.
} 
the current Internet governance entities have decision-making processes which are rather complex and not akin to what is customary in democratic countries. ${ }^{31}$

As Mueller [11 pp. 218-219] points out, the well-known Internet institutions such as IETF, ICANN, and the RIRs are committed to serving the interests of what they call "the community", that is, a club of insiders - with, in some cases, high personal remunerations. ${ }^{32}$ Furthermore, those institutions are bound to serve the interests of their members, not those of Internet users in general. The members of those institutions mostly comprise commercial interests. A detailed and thorough discussion of these matters is found in [3 Chapter 6], which shows in particular how the IETF is dominated by certain manufacturers; as the cited authors say: "... leadership positions in the organization required substantial time commitments, and only a handful of corporations were willing and able to employ staff who spend the majority of their time on IETF business." See also [90 p. 559].

At an overall level, the multi-stakeholder model is not truly democratic: on the contrary, it gives more weight to the relatively less democratic components, such as private companies, as opposed to the components who are supposed to be relatively more democratic, the governments; a more detailed discussion is given in [18, 21]. As Sutherland [97] puts the matter "Multistakehoderism, apparently by design, is neither representative nor accountable"; and it gives more weight to the interests of developed countries [2]. Improved accountability and greater democracy are required $[17,96$ section 3.2(b, 98]. As Powers and Jablonski [3 Chapter 6] put the matter: "For many in the developing world, the ITU is the preferred forum for discussing questions of internet governance precisely because it is based on a traditional UN, one-state, one vote model. Regardless of stakes for the private sector, each state has equal say in policymaking process. It is, thus, an ideal forum to discuss the economics of the internet industries without fear or pressure from

\footnotetext{
31 For example, ICANN has no membership, so its Board cannot be elected in a conventional manner. Half of the members of the ICANN Board are selected by a Nominating Committee, the other half are selected by various other committees, see the ICANN Bylaws. See also McCarthy (2012).

IETF does not have a formal membership. The selection process for the IESG, the body that makes formal decisions regarding IETF standards, is complex, involving a nominating committee and the ISOC Board of Trustees, see RFC 2727.

ISOC has a rather complex process for selecting the members of its governing body, the Board of Trustees: "ISOC By-Laws and Policies call for the Trustees on its Board of Trustees to be elected or selected by various constituencies, namely Organizational Members, Chapters, the ISOC standards organization embodied by the Internet Architecture Board (IAB) and Individual Members. The Board of Trustees itself is empowered to appoint a limited number of Trustees over and above the constituency-based Trustees", see:

$<$ http://www.internetsociety.org/who-we-are/board-trustees/policies-andprocedures/selection $>$ accessed 10 May 2013.

32 See footnote 5 of [11 p. 219]; and the US tax declarations filed by ISOC (Form 990), according to which its Chief Executive Officer was paid some US\$ 500'000 per year

$<$ http://thebigliesociety.yolasite.com/resources/541650477_200912_990. pdf $>$ accessed 6 January 2014.
}

internet and telecommunications companies whose interests reside in shaping opinions and rules in their favor."

As noted above, the Internet has expanded and become an essential component of most economies under the current governance model. However, as already noted, some aspects of the current Internet have been criticized. As Taylor [103] points out, while the Internet does have some leveling effects, it also has exactly the opposite effects, perpetuating and even exacerbating offline inequalities; as we will see later, new dominant companies have replaced old dominant companies, but the problem of concentration remains. Thus it cannot be said that there is consensus regarding the merits of the current governance model. Nor can it be said that the current governance model is truly multi-stakeholder: as noted above, many decisions are made by national governments (which are not multi-stakeholder); in particular, decisions regarding surveillance and limitations on access to content are not made by multi-stakeholder mechanisms; and decisions regarding financial matters are mostly made by private companies, through commercial negotiations.

Thus calls for continuation of the current multi-stakeholder model for Internet governance are in reality calls for a continuation of the current governance system: national governments retain their power nationally, private companies retain control over financial matters, in particular at the international level, where there is no effective regulatory framework; ${ }^{33}$ and the US retains its privileged role ([30, 104]. As Powers and Jablonski [3 Chapter 1] put the matter: " ... at a basic level, US internet policy can be boiled down to getting as many people using the network of networks as possible, while protecting the status quo legal, institutional and economic arrangements governing connectivity and exchanges online." And this is so as to favor the continuing dominance and profitability of US companies, and US geo-economic and geopolitical interests. As the Indian government reportedly puts the matter [105]: "India feels that the very term multi-stakeholder was something of a 'misnomer', a small unrepresentative group of certain individuals, supported by vested interests, appears to have arrogated themselves the right to present certain views in discussions relating to Internet governance. It was not clear as to who they represent and whether who they claimed to represent had in fact nominated them. These persons undermine the positions of the government and were really spokespersons of certain Western interests."

Chaturvedi [106] calls on the government of India to reverse its long standing efforts to change the status quo, and this on the grounds that a move to intergovernmental coordination and supervision would have the following negative effects: (1) only governments participate in

\footnotetext{
33 Note in this context the strong opposition to various proposals presented to WCIT regarding financial matters [20].
} 
decision making and many are not truly democratic; (2) international treaties supersede the rights and duties of national parliaments; (3) decisions made in the UN might threaten freedom of speech; (4) the rules for participation in intergovernmental deliberations are set by governments; (5) the Internet moves fast and government intervention might slow it down and stymie its "permissionless innovation"; (6) decisions might be made by people who lack the requisite expertise; (7) there is no recourse against a badly drafted treaty that has unintended or unwanted effects.

Some of these points are refuted above and in the papers cited above; others reflect a gross misunderstanding of international law. In summary: (1) private companies are among the least democratic organizations in the world, thus a call to avoid government intervention is actually a call to reduce democracy; (2) treaties are binding only after they are ratified, which normally involves national parliaments, thus they do not in any way supersede national parliaments; (3) all UN decisions must conform to human rights law, much of which is customary law enunciated in the Universal Declaration of Human Rights; the "threat to free speech" canard was much bandied about in the context of WCIT and has no validity, [20]; (4) indeed rules for participation should be set democratically and allowing governments to set them is far more democratic than allowing private companies to set them; (5) indeed some government rules might prevent certain innovations, such as clever ways to violate copyright or propagate child pornography; there is no evidence to suggest that, in the current privatised and liberalized environment, government intervention could stymie innovation: on the contrary, proponents of net neutrality call for government intervention precisely to enable innovation and to stymie abuse of dominant power; (6) of course decisions should be made by people who have the requisite expertise, but, at present, decisions which have significant public policy aspects are made by technicians who have no understanding of the issues, resulting, for example, in serious erosion of privacy; (7) national courts can and do correct undesirable interpretations of treaties and any state can at any time denounce a treaty or propose that it be revised.

The weakening of international frameworks so as to favour the interests of developed countries and their private companies is of course not restricted to the Internet: it is a general recent phenomenon [107, 108]. But note that a strengthening of international frameworks is advocated by developed countries and their private companies when such strengthening could favour them, for example with respect to intellectual property laws $[109,110]$

\subsection{The Role of Governments}

Not surprisingly, the proponents of maintaining the current system are primarily those governments that exercise significant power at present (in particular the US and its close allies), private companies, and governments whose private companies reap profits under the current system (primarily developed country governments) [111]. As the US Government put the matter [112]: "The United States government believes that existing multistakeholder institutions deserve significant credit for the Internet's global growth and dynamism and should remain the cornerstones of the Internet governance ecosystem. Multistakeholder organizations should continue to evolve alongside changing technologies and stakeholder needs and to address all relevant opportunities and challenges. Governments should participate meaningfully in this system, and may also play an enabling or facilitating role to help the multistakeholder system to function well. Finally, governments should ensure that the proper incentives and environment are in place domestically so that a single, interoperable Internet can flourish globally, enabling freedom of expression and economic prosperity."

As already noted, some take the view that governments should simply be "one more stakeholder", with the same rights as any other stakeholder, while others take the view that governments have specific roles and responsibilities for public policy matters. ${ }^{34}$ For what it is worth, recent research regarding multi-stakeholderism in the field of enforcement of intellectual property rights suggests that it does not work well for making decisions about public policies prior to those made by the appropriate public decision-making bodies, even if those decisions are non-binding [113]. Such a finding may or may not be relevant for Internet governance in general. And proposals to allow private companies to influence regulations by participating directly in negotiations with government representatives in the context of international trade agreements have been criticized [114].

More fundamentally, Article 21 of the Universal Declaration of Human Rights and Article 25 of the International Covenant on Civil and Political Rights provide that everyone has the right to take part in the conduct of public affairs, directly or through freely chosen representatives. That is, everyone has the right to take part, directly or through freely chosen representatives, in public policy decisions, where "public policy decisions" refers to decisions that affect public affairs. This human right of course also applies to public policy decisions regarding the Internet, by virtue of the principle that offline rights apply equally online [21 section 2]. That principle is enshrined in two UN Resolutions which affirm that the same rights that people have offline must also be protected online. ${ }^{35}$

Thus the principle that people, either directly or through

\footnotetext{
${ }^{34}$ For a good analysis, which clearly outlines additional historically divergent views, see [61].

Resolution A/HRC/RES/20/8, The Promotion, protection and enjoyment of human rights on the Internet and Resolution A/RES/68/167, The right to privacy in the digital age, respectively $<$ http://ap.ohchr.org/documents/dpage e.aspx?si=A/HRC/RES/20/8 $>$ and $<$ http://www.un.org/en/ga/search/view_doc.asp?symbol=A/RES/68/167>
} 
their chosen representatives, have the right to make public policy decisions also applies to public policy decisions regarding the Internet. This principle is correctly embodied in 35(a) of the Tunis Agenda, which states that policy authority for Internet-related public policy issues is the sovereign right of States. ${ }^{36}$

Various calls for non-government entities to participate on an equal footing with governments in decision-making regarding public policy matters would appear to be inconsistent with fundamental human rights, because, as noted before, such non-government entities may not be democratic and would likely weaken the right of people to take part in the conduct of public affairs through their chosen representatives. The opposite view is taken by Doria [115], who states that "Full representation requires multistakeholder representation and that is a basic democratic principle"; that non-government stakeholders should participate in decision-making on an equal footing with governments; and that "It is often Non-Governmental Organizations that serve [human] rights and cross-border interests without discrimination based on geography, nationality or other circumstance." Needless to say, the author disagrees with that assumption.

An even more extreme view has been expressed by Dourado [116], who states that "Insofar as stakeholder communities elect to participate in Internet governance processes on their own account, governments should not have a primary role in Internet governance." Taken to the limit, this means that anti-copyright movements could elect to participate in Internet governance processes on their own account, and those governments would have no power to stop their implementing ways and means to defeat copyright laws. (And the same could be said for gambling, distribution of prohibited substances, pedophile images, etc.) It appears that Dourado is well aware of the implications of his statement, because he also states that "... we should conceive of the role of government as a subordinate one. Governments ... do not have the right to advance positions that contradict the consensus of other domestic stakeholders because such exercises of government power do not reflect the consent of the governed and are therefore illegitimate". Again, this implies that, for example, the US government could not prohibit online poker because the poker-playing community did not consent to that prohibition. In Dourado's view, “... any process that relies on governments to represent the views of domestic stakeholder communities when those communities do not consent to that representation is illegitimate and exclusionary." Needless to say, the author disagrees with such views, in particular because any "community" could claim, ex post, that it was not represented property if it does not like a particular decision (e.g. dealers in counterfeit

36

$<$ http://www.itu.int/wsis/documents/doc_multi.asp?lang=en\&id=2267|0> pharmaceuticals might claim that they were not represented when policies were passed to make such activities illegal). Dourado states “...Internet governance has so far been effected without the implementation of any clearly articulated role for governments at all", thus apparently ignoring the extensive development of law and case law that is specific to the Internet. ${ }^{37}$

In order to justify reducing the role of governments in Internet governance, it has been stated that traditional models of governance which would institutionalise control of the Internet by governments and inter-governmental organisations would not allow all stakeholders to share knowledge, experience, skills and best practice in order to develop policies to address new opportunities and new challenges; such formal, institutional and decision-making models would not be able to keep pace with the rapid technological change that is so characteristic of the Internet and the rapidly-evolving needs and desires of internet users; any attempt to introduce such traditional models would act as a brake on innovation and limit access to the full benefits of an open Internet; it would risk stifling the dynamism that has allowed the internet to deliver so many benefits and opportunities for economic growth and social welfare. ${ }^{38}$ However, it is difficult to find example where government intervention has actually had such an effect - except for restrictions on freedom of speech which, as noted earlier, are pervasive and have surely slowed innovation, for example for web sites based on foreign content, for the development of social networks, and for the development of certain types of entertainment such as online poker. ${ }^{39}$ And it is worth noting that the proponents of the multi-stakeholder approach actually promote the criticized traditional model for certain types of issues, such as intellectual property $[62,89$ p. 192,117$] .^{40}$

Indeed, the US exercised its traditional governmental powers very openly and explicitly, not just domestically, but also internationally, in particular until recently with respect to management of Internet domain names and addresses (through the IANA contract and the contract with Verisign for the authoritative root server [30]), and with respect to surveillance of Internet traffic [72, 118-120]. Further, the US does not adopt the multi-stakeholder model

\footnotetext{
${ }^{37}$ But perhaps this is not what Dourado meant to say, because in the next sentence he focuses on coordination of global Internet resources, which is a very specific issue. According to Dourado, governments are not needed for that coordination (which is obvious) and the question is whether other stakeholder groups want governments to represent them. This begs the question of how the public interest is best served and whether government intervention may be necessary in order to ensure competition and a level playing field. For example, it is not disputed that the public interest is better served when governments coordinate radio frequencies than when the coordination is left entirely to the private sector. So the question is whether the same is the case for global Internet resources such as domain names and IP addresses.

${ }^{38}$ See for example the UK contribution to CWG-Internet, CWG-Internet $3 / 3$.

For the US restrictions on online poker, see $<$ https://en.wikipedia.org/wiki/United_States_v._Scheinberg $>$ accessed 5 December 2013.

Also see the cited UK contribution to CWG-Internet.
} 
when negotiating international trade treaties [121, 122], or certain other Internet-related matters [62]. It is not clear whether the cited comment above criticizing traditional models was intended as a call for change to such exercise by the US of its traditional powers, or not (because the source is usually a staunch supporter of the status quo).

It is worth noting at this point how emotionally-laden words are used to influence the discourse. The terms "free and open Internet" and "rapidly evolving" are contrasted with "institutionalised control" and "slow decision making" - but not for what concerns intellectual property, in which case the terms that are typically used to deny the legitimacy of certain new technologies and behaviors (such as file sharing) are "piracy" and "theft". Since, as noted earlier, existing laws and legal principles tend to be applied by analogy to new technologies, including the Internet, metaphors matter and can significantly affect decisions regarding what is and what is not allowed or encouraged $[123,124]$. The term "decentralized" is often used to describe the Internet. It is true that much of the Internet's operations are decentralized [46], but this is also true of today's telephone system (as opposed to the telephone system in 1960). Indeed, at the lowest layer, the telephony and Internet infrastructures are often the same, so they exhibit similar degrees of decentralization or concentration. But many aspects of the Internet are, at present, far more centralized or concentrated than telephony. Consider the highly centralized management of Internet domain names and address by ICANN, or the high concentration of services such as search engines, social networks and music downloads [125]; see also section 6 below.

It is often stated that the Internet has been an important factor in facilitating the emergence and increase in civil liberties, in particular in countries which have not historically been democratic. But a careful empirical study concludes that in fact mobile technologies are far more significant in this respect [126]; this conclusion is not surprising given that, as noted above, mobile phones are far more available in many countries than is the Internet. It is often said that developments regarding the Internet are very fast compared to the "glacial" pace of developments of technologies governed in more traditional ways [127]. But in fact it took 16 years to create the first set of new generic Top Level Domains (gTLDs) and another 12 years to create the second set; ${ }^{41}$ and the IPv6 protocol was published in 1998, but 16 years later was used only for a very small proportion of Internet traffic. ${ }^{42}$ This is not to say that other aspects of the Internet have not developed quickly, but those aspects are mostly related to applications and services, not to the core network. And applications and services have also been developed quickly for mobile technologies. So it is misleading to compare fast development of Internet applications and services with

\footnotetext{
${ }^{41}<$ http://en.wikipedia.org/wiki/GTLD $>$ accessed 8 April 2014.

$42<$ http://en.wikipedia.org/wiki/IPv6> accessed 8 April 2014.
}

allegedly slow development of core network standards for technologies other than the Internet.

It is also worth noting how misleading analogies are often employed to lead the reader to believe that there is something uniquely positive about the current Internet governance arrangements. For example, Souter [128] states "The development of the Internet has not been overseen by intergovernmental agencies and national governments in the same ways as, for example, telecommunications. Instead, its development has been facilitated by entities in which Internet technical professionals, private sector businesses and other non-governmental stakeholders have been at least as prominent as governments." The first sentence is correct. The second sentence ignores the privatisation and liberalization of telecommunications that has taken place since the mid 1970's. At present, the development of all telecommunications technologies is driven primarily by private businesses, which are indeed more prominent that governments. And this also holds for the development of most other areas of economic activity. Thus, a statement such as "The Internet has become such a fantastic success because it was based on a governance structure that was open to all interested stakeholders, global in reach and guided by a cooperative spirit between all involved parties" [129] in reality applies to most areas of economic activity, and applies for sure to mobile telecommunications which, as shown below, has actually grown faster than Internet, without being "governed" by some special so-called multi-stakeholder model.

As a former US government member put the matter: "A major reason why government is failing to provide leadership is because, as we have seen, big corporations have become so effective in recent years at preventing government from doing much about the environment or any other issue that may require corporations to change in ways they'd prefer not to." [130], and indeed this has tended to be the case in discussions on governance in various domains: corporations influence formal governmental and inter-governmental policies in order to prevent decisions being taken that could negatively affect their commercial operations, and in particular their profits. For a detailed discussion of the influence of US corporations on US policy regarding economic matters related to information and communications technologies see [131 Part Three: The Geopolitics of Information, 3 Chapter 3]. As Powers and Jablonski [3] put the matter: "At a basic level, US internet policy can be boiled down to getting as many people using the network of networks as possible, while protecting the status quo legal, institutional and economic arrangements governing connectivity and exchanges online. From the global infrastructure facilitating exchanges of data to the creation of unique content and services online, American companies are dominant, extraordinarily profitable and, in most cases, well ahead of foreign competition". The cited authors explain, in Chapter 4 of their book, how US policy results 
in the observed dominance and profitability of US companies. Gurstein [104] makes the same point.

Shaw [132] shows how companies active in the US surveillance programs contribute generously to the election funds of key members of the US Congress. Harris [111] discusses how private interests have affected Internet governance in general, and ICANN's decisions in particular, in ways that may be contrary to the public interest (in this regard, see also [98]). Of course such lobbying by private companies is not restricted to telecommunications. For example, pharmaceutical manufacturers influence government policies in order to maximize their profits [133]. To the extent that private companies rely on public funding to develop or distribute products, they are in effect benefiting from subsidies [134]. In telecommunications, it is generally believed that the connection to the end user (often called "the last mile" [135]) is, in many cases, a natural monopoly [136] which therefore must be regulated in some way. This view is not shared by all governments, but the results of lack of regulation of the last mile have been criticized [137] and have led to network neutrality regulation, including in the United States.

Regarding the high-level products and services offered on the Internet, there is a clear concentration in certain sectors, such as search engines, advertising, and access to certain types of entertainment [138-140]. Whether such concentrations are due to natural monopolies, and whether or not they should be regulated at the national or international level are topics that will surely be discussed in the future. Marwick [141] presents an account of how the culture of the founders of new social media companies may lead to a bias in favor of hierarchical, concentrated entities, which is paradoxical considering that the Internet was meant to be a decentralized, uncontrolled network (in this context see also [103]). The financial issues arising out of the concentration of international Internet traffic (whether by national gateways or by international operators) have long been discussed, albeit with little agreement [48]. The lack of agreement is due to ideological differences but also to economic realities, as Hruska [142] puts the matter: "Under the current unregulated [Internet] peering system, foreign ISPs [Internet Service Providers] pay US ISPs a fee to carry internet traffic, which means US companies make a tidy sum of cash off foreign access".

It is generally agreed that competition brings benefits. But a hand-off attitude to markets does not necessarily result in competition. As $\mathrm{Wu}$ [86] puts the matter, governments should act as checks to private power, not as an aid to it. Indeed, as early as 1776, Adam Smith had recognized that private companies will attempt to influence public policies so as to reduce competition, realizing that profits are higher in non-competitive markets; thus the role of governments includes taking measures to maintain competition [143 pp. $68 \mathrm{ff}$.]. And indeed there has been intensive debate in some countries (in particular in the
United States) regarding what policies regarding use of infrastructure would best promote competition for Internet services $[144,145]$. A cynical observer of such debates might be tempted to comment that they were largely struggles regarding which private companies should reap the greatest profits from the use of infrastructure which might better be managed as a public good [146]. In this light, before deciding what role governments should or should not have with respect to Internet governance, one should determine whether or not the current arrangements have worked well. This can be referred to as result-oriented legitimacy [147, p. 103].

\section{Results of the Current Arrangements}

As noted briefly above, it is not correct to state that the number of Internet users has grown faster than other technologies. On the contrary, the growth of mobile telephone subscriptions has been faster than the growth of Internet users, as shown in Figure 1 below (the upper line shows mobile subscriptions, the lower line shown Internet users; the source for the data used to produce this chart, and the subsequent charts, is ITU for the Internet users and mobile subscriptions, and the United Nations Population Division for the number of people). ${ }^{43}$ All the charts show world-wide data, that is total numbers for the world.

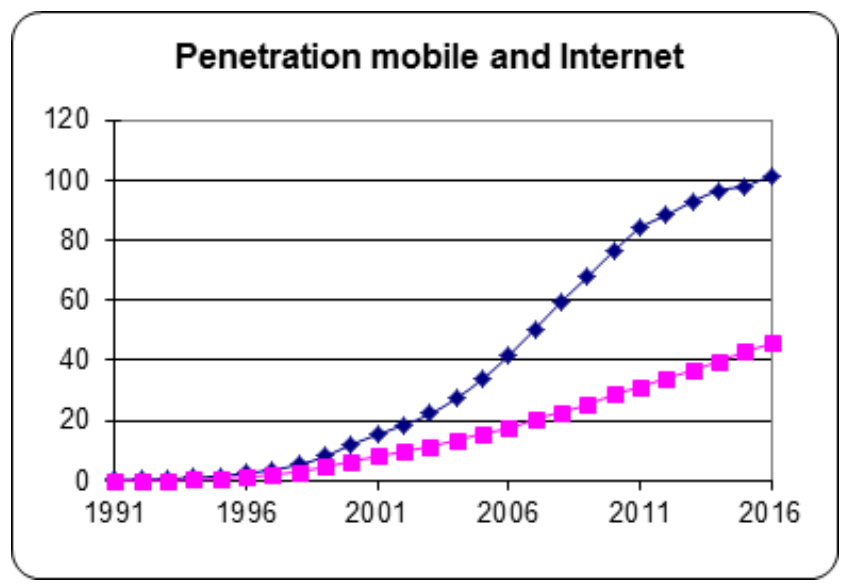

Figure 1. World-wide penetration of mobile subscriptions and Internet users

It is instructive to look at the actual numbers, but in a logarithmic scale. Figure 2 below shows the logarithms of the total number of mobile subscriptions and of Internet users.

\footnotetext{
${ }^{43}$ It is important to note that the two time-series measure somewhat different things. The number of Internet users is an estimate of the number of people that have access to Internet. The number of mobile subscribers is the number of active mobile subscriptions; some people have more than one subscription and some subscriptions are used by machines. Nevertheless, the data provide an overall view of the actual use of the two telecommunications technologies.
} 


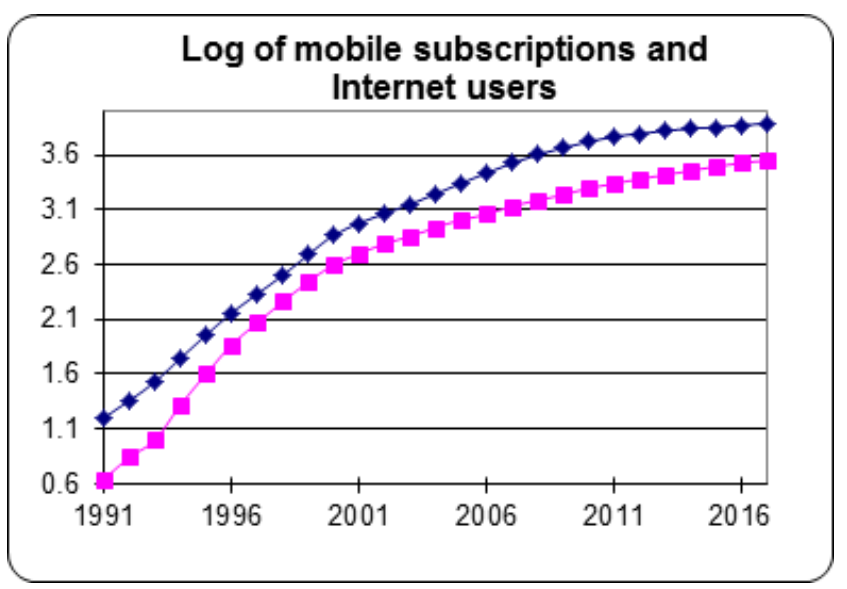

Figure 2. Logarithms of total world-wide number of mobile subscriptions and of Internet users

It can be seen from the Figure 2 (the upper line shown mobile subscriptions, the lower line shows Internet users) that Internet grew somewhat more rapidly than mobile from 1991 to about 2000, then grew more slowly. This can be explained by the fast growth in developed countries during that period, followed by slower growth when developing countries started adopting both technologies. The different growth rates are seen more clearly if one looks at the ratio of Internet users to mobile subscriptions, in Figure 3 below.

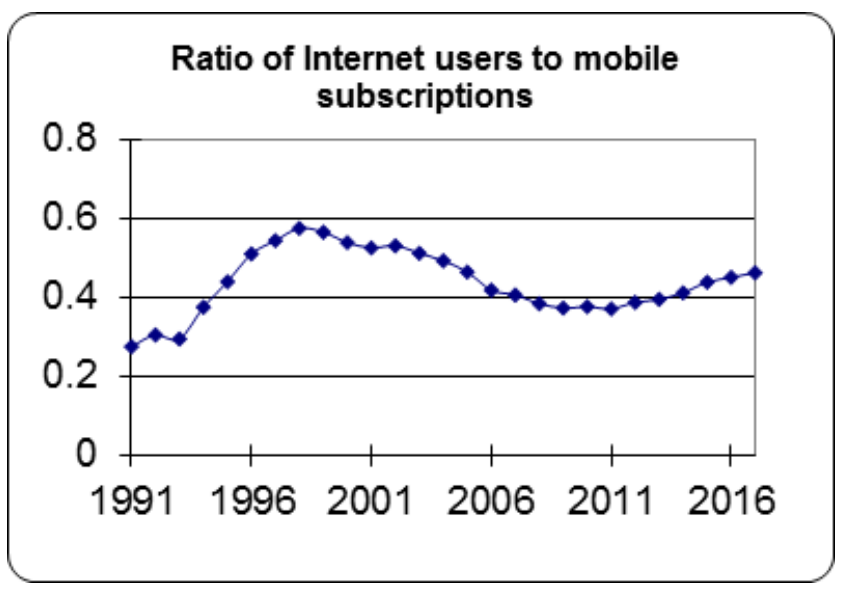

Figure 3. Ratio of total world-wide number of Internet users to mobile subscriptions

From 1993 to 1998, the ratio increased, meaning that growth was relatively higher for Internet users. Then the ratio decreased, meaning that growth was relatively higher for mobile subscriptions. The ratio appears stable since 2009 , meaning that the growth rates are comparable. However, Internet growth has appeared to again become relatively higher as of 2015: developing-country markets have reached saturation for mobile telephony and new developing-country users use their mobile telephones to access the Internet. See also [148 para. 2.3.1(k)].

It is not disputed that the price of connecting to the Internet for users in developing countries is, in relative terms, much higher than the price for users in developed countries [149, 150]; and Supplement 2 to Recommendation ITU-T D.50, section 2, whereas that is generally not the case for mobile telephony. It is not disputed that the relatively higher prices for Internet access are undesirable in terms of promoting access to Internet and should be addressed [148 para. 2.3.3(a), (d), (e) and (f)]; however, there is no agreement on how best to address the issue (see for example the discussions at WSIS, WCIT, and in ITU-T Study Group 3). ${ }^{44}$ And it should be noted that widespread use of mobile telephones has resulted, to date, in significant benefits in developing countries, a well-documented example being fishing in parts of India $[151,152]$; another example being financial transactions [153]. Further, a careful empirical study concludes that mobile technologies (as opposed to the Internet) have had a unique and persistent effect on the emergence and increase in civil liberties [126].

The data presented above may suggest that the relatively high price of Internet access may account at least in part for the relatively slower growth rate of Internet compared to mobile telephony. The differences between the governance arrangements for the Internet and for other telecommunication technologies may have had an effect on end-user prices (see section 2 of Supplement 2 to Recommendation ITU-T D.50) and the relatively higher penetration of mobile compared to Internet, but there are many confounding factors (including the cost of the end-user equipment and the fact that literacy is required to use the Internet), so it is impossible to say whether the Internet would have had higher or lower penetration and growth rates under traditional governance mechanisms. Further, there is little data available regarding Internet connectivity costs and prices at the wholesale level, because that business is mostly conducted as a barter economy, under informal "no charge" arrangements [50] (but such informal arrangements might be challenged by forthcoming initiatives regarding taxation [154] or in order to promote competition [155, pp. 11-12].

One of the justifications for privatization and liberalization are that they should result in increased competition, which in turn should engender lower prices and more choices for end-users. However, some portions of telecommunications markets may be natural monopolies and many portions are subject to network effects [156]. Thus, deregulation may not always result in competition. Indeed, Noam [157] presented an empirical analysis of the effects of deregulation in the US (including regarding the Internet), concluding that pro-competitive measures may have favored greater concentration, and thus less actual competition. Noam [158, 159] presents results of an ambitious world-wide study of media concentration (including ISPs, search engines, etc.); the results are

${ }^{44}$ See however the previously cited Supplement 2 to Recommendation ITU-T D.50 and WTPF-2013 Opinion 1. 
consistent with his previous findings, which is not surprising because, as Noam notes, the high fixed costs, low marginal costs, high economies of scale, and high network effects typical in these industries favor concentration. Burch [160] notes that the rate of concentration appears to be increasing.

It would be beyond the scope of the present paper to conduct an updated empirical analysis of concentration, however it is worth noting that, in 2013, and in 2017, 14 information technology and communications companies were among the 100 largest companies in the world (the list includes Apple, Samsung Electronics, AT\&T, China Mobile, IBM, Microsoft, Google, Intel, Cisco). ${ }^{45}$ Some of these companies have strong (or event dominant) positions in certain portions of the Internet market. This may or may not be related to the current Internet governance arrangements, under which there is relatively weak government control at the national level and essentially no intergovernmental control at the international level. And this may or may not be in the best interests of consumers [87]. It is worth noting that, of the telecommunications operators in the top 100 mentioned above, only one (Vodafone in 2013) is large around the world; the others are large either in their national market (AT\&T, China Mobile, Nippon Telegraph and Tel, Comcast) or in regional markets (Telefonica, America Movil). In contrast, the other large companies in the top 100 are all large around the world. Thus, this limited set of data suggest that there may be concentration at the worldwide level for information technology and Internet companies, whereas concentration may tend to occur more at the national (or regional) level for mobile and fixed telecommunication operators.

Regulatory and technical factors may contribute to such relative differences in concentration. Fixed and mobile telecommunications operators must obtain national licenses, whereas information technology and Internet companies typically do not need national licenses. Names and addresses for fixed and mobile networks are primarily assigned at the national level, whereas global domain names can be easily obtained. For sure there are global telephone numbers (see Recommendation ITU-T E.164.1) but they are relatively hard to obtain and, even when they are obtained, they are not automatically routed: as noted above, there is no automatically synchronized global database for telephone numbers, so an entity that obtains a global telephone number must negotiate routing agreements with operators in each country where it wishes to use the number. Thus, it is relatively difficult to set up a global service based on telephone numbers, whereas it is relatively easy to set up a global service based on domain names. So it is not surprising that global services (such as music download sites and social networking sites) are provided using domain names. Another technical

\footnotetext{
${ }^{45}<$ http://www.forbes.com/global2000/> accessed 3 December 2013.
}

difference is in the very nature of the information provided: a domain name points to a collection of text and graphics; a telephone number points to verbal information (or perhaps some short text messages, but those are not centrally stored - except perhaps by government surveillance systems and are ephemeral). Thus it is logical and relatively simple to implement a web search facility, whereas it is hard to envisage a "voice communication" search facility (again, except perhaps in the case of entities that conduct massive surveillance).

So both regulatory and technical factors may favor relatively greater global concentration of information technology and Internet companies. And some Internet companies have indeed adroitly exploited these factors to attain significant dominance; as Powers and Jablonski [3 Chapter 1] put the matter: "Building on the analogue to the historical significance of the oil industry, there is no equivalent company that has ever been capable of dominance in each facet of the oil economy to the extent that Google leads in the data economy." ${ }^{46}$ An alarmist view of this situation is given in [161]. And specific criticism is given in [162]. This of course has an implication for governance: as noted above, national governments have tended to apply existing laws by analogy to new industries, including anti-trust and competition law. Thus, national governments can, at least in principle, take steps to curb abuses of dominant market power by national companies. On the other hand, it is much more difficult for national governments to take actions against companies whose dominance is global, not national. This suggests that the companies that have significant market power at the international level may be keen to avoid any international frameworks that might make it easier for governments to control them, and indeed such companies have actively lobbied against discussions that could potentially have led to some sort of framework [20]. ${ }^{47}$ In contrast, there have been calls for governments to control some aspects of services provided to consumers located in their jurisdiction, in particular to protect their right to privacy [163].

Indeed, as noted earlier, each of the components of a multi-stakeholder model will strive to obtain outcomes that meet its interests: private companies will strive for outcomes that allow them to maximize profits, states will

\footnotetext{
${ }^{46}$ A detailed analysis is given in [3 Chapter 4], which explains how the discourse of Internet freedom is intimately related to Google's business model and profitability: more interconnected users providing more information results in more profits, in particular because targeted advertising becomes more valuable.

47 With respect to the WCIT, it is worth noting that lobbying by mobile operators resulted in only relatively weak provisions regarding roaming being agreed, whereas lobbying by information technology and Internet companies resulted in a refusal by some countries to sign the new International Telecommunication Regulations (ITRs), even though that treaty did not in reality place any constraints on their businesses [20]. It would thus appear that the large international players may have relatively more influence in intergovernmental discussions than do the large national players. Or perhaps this is due to the fact that those large international players are mostly US companies, that the US political system is relatively more responsive to industry lobbying, and that the US has significant ability to influence intergovernmental discussions.
} 
strive for outcomes that allow them to maintain control, and civil society will strive for outcomes that meet their particular concerns (such as free speech). For the reporting year ending March 2013, one of the larger international mobile operators, Vodafone, had about 400 million customers and $\$ 73$ billion revenue for 91'000 employees, with an average after tax profit of about $\$ 9$ billion for the years 2009-2013. ${ }^{48}$ By way of comparison, one of the larger Internet companies, Google, had, for the reporting year ending December 2012, about $\$ 11$ billion net income, $\$ 50$ billion dollars revenue for 54'000 employees (the net income increased every year from 2008 to 2012; the five-year average was about $\$ 8$ billion) ${ }^{49}$ Thus it is not surprising that Google has significantly increased its lobbying activities [164]. Google's income and revenues in 2016 nearly doubled with respect to 2012 . The propensity of private companies to maximize profits explains the slow uptake of IPv6 [165-167]. A good account of the complex discussions and conflicting interests that led to the adoption of a protocol (IPv6) that is not backwards compatible (which has made the uptake difficult to justify in commercial terms) is given in [168]. While a respected expert has stated that the slow uptake of IPv6 may represent a case of market failure [169], the present author has argued that it is rather a case of standardization failure, that is, an instance where the current Internet governance arrangements (which in this case were dominated by private companies) did not work very well [170]. Governments may or may not see a need to intervene to accelerate the uptake of IPv6 addresses [170]; in this context, see WPTF-13 Opinions 3 and $4 .^{50}$

As noted earlier, governments do control the Internet nationally (in particular by enforcing national laws that prohibit certain activities), however they have little or no influence at the international level, and this because the US (and its allies) have consistently resisted intergovernmental influence on the Internet (with some exceptions, such as intellectual property). A detailed discussion of recent US actions in this respect is found in [20]. An excellent summary and analysis of the debate is given in [171]. As noted earlier, corporate interests are well represented in Internet governance at the international level. Thus one might expect that corporate interests are well provided for at present, and indeed this is the case $[17,21]^{51}$. Further, it is worth noting that recent calls by key companies for

\footnotetext{
48

$<$ http://www.vodafone.com/content/annualreport/annual_report13/downl oads/

vodafone_annual_report_2013.pdf> accessed 4 December 2013, in particular p. 189.

$<$ http://investor.google.com/pdf/2012_google_annual_report.pdf $>$ accessed 4 December 2013, in particular p. 24 .

50 Available in the previously-cited Chairman's report $<$ http://www.itu.int/md/S13-WTPF13-C-0016/en $>$.

${ }^{51}$ Note also that one well-known company was very profitable; it had, in 2012, some US\$ 48 billion in cash and short-term investments and the amount was increasing, see

$<$ http://www.google.com/finance?fstype=ii\&q=NASDAQ:GOOG $>$ accessed 8 June 2013
}

limits on government surveillance apparently do not include calls to increase the protection of privacy: rather, they may be intended to limit government control of commercial activities [73, 172].

As noted earlier, some take the view that this situation is perfectly acceptable, or even desirable ${ }^{52}$ whereas others take the view that this situation is not optimal because it disadvantages certain geographic areas [2], or economic interests [17, 49, 154 Annex Action 1, 173-175], or favors pervasive government surveillance [16, 176, 177], or erosion of privacy and cybercrime [54]. An excellent account of the dangers of pervasive surveillance is found in [178]; excellent accounts of the dangers of data analysis by private companies are given in $[76,179] .{ }^{53} \mathrm{~A}$ good summary of the shortcomings of the current Internet governance arrangements has been given by a group of civil society organizations [180].

Thus some consider that the current situation is a dystopia. On the other hand, proponents of the current Internet governance model consider that any change is likely to result in a dystopia. Others propose improvements in the current arrangements while maintaining their basic nature [180]. Others propose changes that would result in greater accountability to individual Internet users [182] (in this context, it is worth noting that, in the early conception of ICANN, Internet users at large were supposed to have significant influence $[27,29 ; 183]$. Given the significant political interests of governments to exert control [94], and the significant economic interests of private companies, such proposals are not likely to find consensus. Thus they can be qualified as utopias.

No state has, to date, agreed to relinquish national control over the Internet. Indeed, a resolution of the US Congress (prepared in the context of WCIT) articulated a policy "to promote a global Internet free from government control", but this was omitted when the text was proposed for adoption as a law [184]. And the US and its allies prevented the adoption of language calling for the end of mass surveillance at the April 2014 NETmundial meeting, an outcome criticized by civil society. ${ }^{54}$ The excessive influence of private companies in the multi-stakeholder model was clearly visible at that meeting $[185,186]$. A full analysis of the NETmundial meeting is beyond the scope of this paper. Short overviews are given in [186-188].

Not surprisingly, states agree that they should have a role regarding the Internet, and this is well expressed in the Tunis Agenda. What they disagree about is (1) exactly what that role should be and (2) what, if any, international

\footnotetext{
${ }^{52}$ For example, Dourado [181] argues that informal enforcement by ISPs of certain rules is preferable to formal legal liability.

53 As that article says, when browsing a web site, a targeted advertisement may appear, based on an analysis of the user's previous buying patterns, patterns which have no apparent relation to the web site. And indeed, when this author was reading that New York Book Review online, it contained an advertisement for a Swiss online food shop that this author had used once a few months previously. Harmless? In itself yes, but not as $\mathrm{a}$ an indicator of what can be done, as explained in the cited article.

${ }_{54}<\mathrm{http}: / /$ bestbits.net/netmundial-response/> accessed 26 April 2014.
} 
harmonization is needed. States tend to favor international harmonization only when it appears likely to meet their own interests. Since the interests of states are not, at present, well aligned, it naturally follows that it is difficult for them to agree on international harmonization regarding Internet governance; and it is difficult for the USA to agree to any measures that might reduce its present dominant role. In particular, states disagree on what, if any, should be the specific role of the ITU with respect to international harmonization, even though they have agreed, in various high-level instruments, that there should be such a role [21], and specific proposals have been made. ${ }^{55}$ Be that as it may, one of the key issues underpinning all discussions of Internet governance was, as noted above, the asymmetric role of the United States government $[2,18,111]$. Powers and Jabloknski [3] document in detail how the policies of the US government have facilitated the growth of dominant Internet players which further US geo-economic and geopolitical interests. They cite Nordenstreng and Schiller [189]: "Since World War II, the rhetoric of freedom has been the preferred usage of American corporate monopolies, press and other, to describe the mechanisms of the system that favors their operation", and indeed, as shown by Powers and Jabloknski [3], this has been the case for the Internet.

\section{The Future}

"We stand at a precipice where the great leap in human communication and ingenuity that gave us global cyberspace could continue to bind us together or deteriorate into something malign. Only by fully uncovering the battle for the future of cyberspace can we understand what's at stake, and take steps to ensure that this degradation of one of humanity's greatest innovations does not happen." [54 p. 9]. While this statement refers to cyberwar, cybercrime, and surveillance, it does also apply to Internet governance in general. As a noted scholar put the matter: "The system is failing, conventional policies and institutions are increasingly discredited, and fundamental changes of one form or another are likely to come, for better or worse" [74 p. 221]. According to some, such change was likely to come about by the end of 2015 [190]. But that change did not come about, although the US government did relinquish its role regarding ICANN [18].

It has been posited that the issue of the asymmetric role of the US government could be addressed by the USA relinquishing its current privileged role [95 p. 226], with the existing structures remaining as they are. That is, there would be no new formal agreements involving governments, and the current contracts and agreements

\footnotetext{
55 See in particular the introduction and Annex B of a submission to the US government in response to a request for comments $<$ http://www.ntia.doc.gov/legacy/ntiahome/domainname/dnstransition/co mments/dnstrans_comment0081.htm> accessed 13 June 2013.
}

with the US government would be discontinued. That is what in fact happened [18]. But an alternative would have been for other governments to join the USA in becoming signatories of the various relevant existing agreements, ${ }^{56}$ and possibly new agreements. This would actually have resulted in very little change with respect to the status quo, because the US exercises its power in ways other than formal control of naming and addressing, for example by compelling US-based private companies to disclose information used for surveillance [72, 75]. In February 2012, the European Commission called for globalization of ICANN and IANA, while retaining the current multi-stakeholder model [191]. The call for the globalization of ICANN and the retention of the current governance model was welcomed by the US government, but the US said nothing about the globalization of IANA [192]. Subsequently, the US clarified its position [193], stating that it was asking ICANN to convene global stakeholders to develop a proposal to transition the role played by the US government in the coordination of the DNS, and that it would not accept a proposal that replaces the role of the US government with a government-led or an inter-governmental organization solution. Thus, the US unilaterally decided to give to ICANN the mandate to come up with a proposed change to the current system, while putting pre-conditions on the outcome of the consultations. Further, the US language was interpreted to mean that, in order to retain the IANA function, ICANN would have to remain a private company, and thus be subject to the laws of at least the country in which it is incorporated, the USA. While some welcomed this announcement, others criticized it, fearing that ICANN might lack sufficient accountability [18, 194, 195]. And the proposal drew criticism from some members of the US Congress, who stressed that governments should not be involved (while apparently failing to notice that their involvement belied that point) [196].

Another approach could be to envisage a new governing structure along the lines initially proposed by the IAHC, ${ }^{57}$ which was fully multi-stakeholder. Kuerbis [182] proposes changes to ICANN that would appear to be consistent with that approach. Such an approach could be combined with agreements on basic principles, in particular related to "Internet freedom": there has recently been a flurry of proposals regarding basic principles; including suggesting that Internet freedom includes the freedom to do business across borders [101 pp. $58 \mathrm{ff}$.]. An analysis of specific proposals is given by Jamart [101 pp. $62 \mathrm{ff}$.], but, to date, such principles have not been widely accepted, and initial

\footnotetext{
${ }^{56}$ Regarding ICANN, the Affirmation of Commitments and the IANA Contract. Regarding the authoritative root server, the contract with Verisign. See [30 p. 5].

<http://web.archive.org/web/19971211190034/http://www.gtld-mou.org/> and more specifically

$<$ http://web.archive.org/web/19971211190257/http://www.gtld-mou.org/ gTLD-MoU.html>accessed 10 June 2013.
} 
calls by the US for "Internet freedom" appear to have hit the reality that no state is willing to forego placing some limits on online activity [101 p. 68]. Indeed, it can be said that "everything that is illegal offline is also illegal online" ${ }^{58}$ and the US took a strict approach to this with respect to the release by WikiLeaks of classified internal State Department communications (sometimes called Cablegate) [101 p. 75].

Yet another approach is to call for the creation of some new governance mechanism. For example, noting that traditional governance models don't seen able to solve certain economic and political problems (not just regarding the Internet), it has been suggested that there is a need for new system of governance: "In practice this means that decision-making power must be decentralized as much as possible to communities of active citizens in the domains of their competence. In short, it must devolve and involve beyond the old systems of a mass public choosing distant rulers in periodic one-person-one-vote elections where their voice doesn't matter." [197 Chapter 5]. This is of course a call for corporatism, albeit decentralized corporatism. Not surprisingly, such an approach is favored by corporate interests, because it allows them to exercise greater influence [21]. And of course this is also true for the Internet, in which the approach (which favors the economic and political interests of developed countries) ${ }^{59}$ is referred to as "the multi-stakeholder model" [2].

A different approach would be to envisage the creation of a new Internet governance body, possibly within the United Nations. ${ }^{60}$ A good summary and discussion of such proposals is given in [101 p. 60]. Schiller [7 pp. 359-360] summarizes proposals by various governments, noting that the US rejected those proposals. As an Indian civil society organization argues, it might be better to view the traditional multilateral mechanisms (intergovernmental organizations) and newer multi-stakeholder mechanisms as complementary, with each being best suited for certain types of tasks, rather than as diametrically opposed mechanisms. ${ }^{61}$ In light of the revelations regarding the Prism surveillance program $[73,102],{ }^{62}$ and other unilateral pervasive surveillance, significant concerns have been raised and there have been various calls for change

\footnotetext{
58 Many thanks to prof. Andrea Sirotti Gaudenzi for this pithy formulation.

59 See for example the statement Parminder Jeet Singh at the Second Meeting of the Working Group on Enhanced Cooperation, 7 November 2013

http://unctad.org/meetings/en/SessionalDocuments/WGEC 2013-11-07

Transcript_en.pdf $>$ pp. 7-8, accessed 21 November 2013 .
${ }^{60}$ For example, India's proposal for a United Nations Committee for Internet-Related Policies (CIRP), presented to the $66^{\text {th }}$ session of the UN General Assembly, 26 October 2011

$<$ http://itforchange.net/sites/default/files/ITfC/india un cirp proposal 2 0111026.pdf $>$ accessed 2 December 2013. Hill (2013b) describes another, unrelated, proposal.

${ }^{61}$ Knowledge Commons Brazil < http://www.knowledgecommons.in/brasi 1/2page_id=20> accessed 3 April 2014.

62 It is worth noting that Prism is the successor of a series of increasingly intrusive surveillance programs whose origin dates back to 1898 [198]. An excellent discussion of surveillance and related matters, including cyberwar and cybercrime, in given in [54].
}

$[16,199] .{ }^{63}$ But, as noted scholar Milton Mueller points out, it would be better to regulate surveillance directly, rather than to attempt to regulate it through Internet governance mechanisms [94]. And indeed this is what is proposed in a report commissioned by the US President [95] and this is what is called for in a resolution of the United Nations General Assembly. ${ }^{64}$

Be that as it may, some change will likely take place with respect to Internet governance. As noted above, it is important that such changes result in desirable outcomes, and not in dystopia. Some have taken the view that WCIT could have resulted in changes that would have been a malign deterioration [20, pp. $35 \mathrm{ff}$. and $70 \mathrm{ff}$.]. As this author (and others) has argued at length, such views were exaggerated [20, pp. 71 ff., 52]. Nevertheless, the discussions at WCIT did reveal profound differences $[20 \mathrm{p}$. 68 and pp. $81 \mathrm{ff}$.] and there is a potential for fragmentation of the Internet if the differences are not resolved $[20 \mathrm{pp}$. $141 \mathrm{ff} ., 200]$. In democratic systems, there is usually some formal mechanism to make a decision if no consensus is found. That formal system is usually some kind of voting. In the United Nations (UN), each country is assigned one vote, no matter what the size of the country or the type of government that it has. However, as noted above, some criticize that system on the grounds that not all UN countries are truly democratic (but, as noted above, nor are the several component bodies of the multi-stakeholder model).

Be that as it may, it appears to this author that the Internet has followed the same cycle as that followed by other communication technologies, moving from open crude inventions to closed sophisticated products [86]. As a well-respected technologist put the matter (in the context of a discussion regarding the slow rate of the transition to IPv6) [166]:

"We are witnessing an industry that is no longer using technical innovation, openness and diversification as its primary means of propulsion. ... Today's internet is serviced by a far smaller number of very large players, each of whom appears to be assuming a very strong position within their respective markets. The drivers for such larger players tend towards risk aversion, conservatism and increased levels of control across their scope of operation. The same trends of market aggregation are now appearing in content provision, where a small number of content providers are exerting a dominant position across the entire Internet."

A similar analysis is presented by Foster and McChesney [87]: "we are entering a world of digital

\footnotetext{
63 See also <http://reformgovernmentsurveillance.com/ $>$ accessed 9 December 2013.

64 A/Res/68/167, The right to privacy in the digital age $<$ http://www.un.org/en/ga/search/view_doc.asp?symbol=A/RES/68/167>
} 
feudalism, where a handful of colossal corporate mega-giants rule private empires ... the top 10 Web sites accounted for 31 percent of US page views in 2001, 40 percent in 2006, and about 75 percent in 2010 ...”. For a detailed discussion of the lack of competition in most aspects of the Internet, see [74]; for a summary of the domination of what are commonly called "over the top" services, such social networks and search engines, see [75]; for a summary of how entities that provide cloud services might be creating "walled gardens", see [201]. In this light, the corporatist multi-stakeholder model could be appropriate at the national level in countries where there is an appropriate legal framework to ensure that there is competition and control of abuse of dominant market power.

The management of Internet domain names and addresses, carried out at present by ICANN, presents a special issue. As scholars [202] have noted, at present there is no legal framework to control ICANN's activities, which are largely not subject to competition. Such lack of control no doubt contributes to ICANN's somewhat surprising budget growth, ${ }^{65}$ and to the fact that ICANN is able to charge an annual fee for each domain name under certain top-level domains ${ }^{66}$ despite the fact that there is no actual cost to ICANN for the domain names under the top-level domains. The cited scholars suggest that an alternative might be to break up ICANN so that its activities could be subject to competition; but this could have undesirable side-effects in terms of fragmentation, see below. Harris $[17,93,111]$ is far more negative, suggesting that unless major changes are made regarding ICANN, the Internet could become fragmented. See also above for various announcements and proposals regarding ICANN.

A corporatist multi-stakeholder model might be appropriate at the international level if there were an appropriate international legal framework to ensure that there is competition. To some extent, the instruments of the ITU (in particular the ITRs) and of the World Trade Organization (WTO) (in particular the Annex on Telecommunications and the Telecommunications Services: Reference Paper) are meant to provide such an international framework. But the 1988 ITRs are no longer relevant, and a significant number of countries have not yet

\footnotetext{
65. ICANN's operating budget for 2001-2002 was approximately US\$ 5 million for a staff of 21 full-time equivalents. ICANN's operating expenses in 2012 were about 70 million US dollars, and in 2013 about 140 million dollars. Revenues in 2012 were projected to be some 230 million dollars. Staff was 158 people in 2012, planned to grow to 189 in 2013.

That is, ICANN's operating expenses grew by $30 \%$ per year during the 10 years from 2001 to 2011, and planned to grow $100 \%$ from 2012 to 2013 . Staff grew by $22 \%$ per year during the 10 years from 2001 to 2011 , and was planned to increase by $20 \%$ from 2012 to 2013 .

This is of course far higher than the growth rates of the economies of most countries, and far higher than the growth rate of most areas of economic activity. By comparison, an intergovernmental organization such as ITU had essentially no budget growth during the comparable period and in fact reduced its staffing.

${ }_{66}$ See for example 7.2 of the ".com" registry agreement $<$ https://www.icann.org/en/about/agreements/registries/com/agreement-0 1dec12-en.htm> accessed 7 December 2013.
}

acceded to the 2012 ITRs [20]; and the WTO instruments are also dated and do not address the key issues regarding the Internet that are outlined above. Thus, at present, there is no suitable international legal framework under which the corporatist multi-stakeholder model could be considered to be appropriate. It is thus not surprising that the current discussions reflect many of the issues identified by Baran [5], in particular the consequences of the lack of international agreements regarding issues related to security ${ }^{67}$ and the need to ensure competition. In the absence of international agreements, there is a risk of fragmentation [203, 204]; as Raymond and Smith [71] put the matter when analysing the potential consequences of the failure to reach consensus regarding the 2012 ITRs:

"the larger problem [of the split between signatories and non-signatories] in the long term is the overall degree of complexity introduced into the governance of international telecommunications, the potential for increased transaction costs and the eventual possibility of significant divergence between the two treaty regimes over time. Given the similarity between the two treaties [1988 versus 2012], as well as the long history of routine cooperation on international telecommunications and the resulting business relationships and accumulated social practice, there are reasons to believe that this complexity may be manageable, if suboptimal. This assessment may not apply, however, in the event that the parties to the new ITRs engage in subsequent negotiations, building on the accompanying resolutions to erect a parallel institution for Internet governance. In the event such a parallel institution duplicates the function of the Internet Assigned Numbers Authority or the IETF, the potential exists for serious harm to global interoperability. Further, since routing is currently done without regard for international borders, the existence of parallel Internet governance regimes that may evolve with very different privacy protections poses challenging questions about the sustainability and desirability of legacy routing practices."

As suggested elsewhere [21 section 7], the ITU would appear to be a proper forum in which to conduct some of the discussions regarding what, if any, international framework agreements would be appropriate for the Internet, and this despite the failure to agree at WCIT [20 p. 141]. A contrary view of the risk of fragmentation, and of the role of intergovernmental organizations, is given in [204].

\footnotetext{
${ }^{67}$ Baran [5] prophetically foresaw the potential for the government surveillance that has actually been put into place: "Highly sensitive personal and important business information will be stored in many of the contemplated systems ... At present, nothing more than trust —or, at best, a lack of technical sophistication-stands in the way of a would-be-eavesdropper."
} 


\subsection{The "Federated Internet"}

Discussions regarding an appropriate international framework might result in agreements to move to what noted scholar Eli Noam refers to as a "federated Internet" [202]. At present, there hasn't been much discussion regarding what form exactly such a federated Internet would take. Paradoxically, it is conceivable that it would be "back to the future" and that it could resemble in some ways the telecommunications technologies that preceded and coexist with the Internet, such as telephony. According to Mueller [11]: "A consistent root for domain names and a coordinated IP address allocation regime make it possible to have one Internet that connects everybody, as opposed to a bunch of different Internets, driven by different policies and fenced in by territorial permissions". This is correct, but there could be other ways to ensure a root that is sufficiently consistent, and IP address allocation that is sufficiently coordinated, to allow adequate interconnectivity, even if there is some variation in policy. It should be noted that territorial permissions exist anyway today, in particular regarding restrictions on freedom of speech; in policies regarding domain name registrations: some country-code top-level-domains (ccTLDs) require that the registrant have some link with the geographic region they cover, others do not, and there are some variations regarding the dispute resolution policies for ccTLDs; and in IP address allocation: the policies of the regional Internet registries (RIRs) are not identical.

In order to understand why a federated Internet might resemble, in some respects, other telecommunications technologies, it is first necessary to dispel some misunderstandings regarding non-Internet telecommunication systems, in particular that their governance is (or was) centralized. Indeed, during discussions of Internet governance, it is not uncommon to hear statements to the effect that the highly decentralized nature of the Internet precludes relying on the governance mechanisms that were used for previous telecommunications technologies (such as telephony) which are highly centralized [202, 204, 206, 207]. Such statements conflate unrelated facts. It is correct that telephone systems were highly centralized at the national level prior to liberalization and privatization. But, at present, telephone services are decentralized in most countries. Further, the telephone system (and for that matter telegraphy) were never centralized at the international level. On the contrary, they always operated as federated systems at the international level, albeit as federated national monopolies prior to liberalization and privatization. For example, toll-free (0800) telephone numbers were first introduced in the USA in 1967 [208], whereas the international standard regarding such numbers was not developed until $1988 .{ }^{68}$ As a result, for many years,

\footnotetext{
${ }^{68}$ Recommendation ITU-T E.152. See also E.169.1.
}

it was not possible to dial a US 0800 number from abroad.

In contrast, while the operation of the Internet has always been decentralized, portions of its governance are centralized, but not at the national level. The management of top level domain names is centralized at the international level by ICANN. The top level allocation of IP addresses is centralized at the international level by ICANN and at the regional level by the RIRs. It is instructive at this stage to consider the profound operational differences between the Internet domain name system and its equivalent in telephony, which is the mapping of telephone numbers (specified in Recommendation ITU-T E.164) to telephone addresses (specified in Q.708 for fixed phones and E.212 for mobile phones). Domain names are mapped to IP addresses through a hierarchical search mechanism [209]. Domain names are fully portable, because the several distributed databases that contain the mapping information are accessed in a way that emulates a single centralized database. At the top level, the distributed databases are synchronized and kept consistent. Thus, it is not possible to introduce a new top-level domain name without the approval of ICANN. And, if a domain name is added under a top-level domain name, it is automatically visible throughout the world. Thus, if the domain name "ca" is added under the top-level domain ".us", then the domain name "ca.us" is visible around the world.

Telephone numbers (which are names) are mapped to addresses using Signaling System Seven (SS7) (specified in the Q.700 series ITU-T Recommendations). But there is no authoritative real-time-machine-readable top-level database. In countries that have no number portability, queries have to be sent to the operator to whom the telephone number was assigned. In countries with number portability, various solutions exist, including central national databases $[210,211] .{ }^{69}$ However, there is no international real-time-machine-readable database. That is, each operator has to make arrangements with other operators regarding queries: there is no automatic hierarchical cascade like that of the Internet domain name system. Thus, when the USA introduced 0800 numbers, they were invisible outside the USA for many years. It is this lack of a single authoritative "root server" for the telephone system that makes numbering misuse possible. Telephone numbering misuse occurs when a number is used for a purpose other than the one for which it was assigned. ${ }^{70}$ A common example is the use of a national number in a high-termination-rate country to provide call-in services (often erotic phone services) to users in a different country without actually terminating the call in the high-termination-rate country. That is, a call made to a number in country $\mathrm{Y}$ from country $\mathrm{X}$ actually stays within country $\mathrm{X}$ while being billed to the customer as if it were

\footnotetext{
${ }^{69}$ For more details, see Supplement 2 to ITU-T Recommendation E.164 <http://www.itu.int/rec/T-REC-E.164-201203-I!Sup2>

${ }^{70}$ Paraphrasing 4 of Recommendation ITU-T E. 156.
} 
terminated in country Y [20 pp. 28, 96]. The equivalent for the Internet would be a situation in which there is no single authoritative master root server. For example, ICANN could be considered a US entity, responsible only for domain names under US jurisdiction (which would presumably include ".com", ".org", “.edu”, and ".mil"). Other domain names, such as ccTLDs, would not be subject to ICANN's authority (as indeed they largely are not at present). There would be many root servers. ISPs (and perhaps even end-users) would be free to choose which root server they use. The root servers would be largely synchronized, because, in general, there is no commercial advantage in not being synchronized. However, in some cases, some root servers might offer additional TLDs, or, perhaps, mask certain domain names. Such a scheme is described in [212].

Needless to say, such a situation regarding the Internet would be anathema to those who believe that all users should have access to all of the Internet's products and services $[213,214] .^{71}$ But, in practice, language barriers are already resulting in a fragmentation of the Internet [215 section 2.1], as are various government censorship activities [216-219]. It is of course well-know that China has long taken measures to restrict what its citizens can access [215 section 1.2]; and at least one government was apparently negotiating with at least one major Internet company to create a national version of a popular video download site, so as to ensure that the videos available in that country are compatible with that country's laws and regulations [220] and Powers and Jablonski [3 Chapter 7] explain in detail how China's multi-faceted approach of government regulation, censorship, monitoring, self-regulation, encouragement of national industry, and protectionism "has been highly effective at keeping Chinese users away from foreign applications and content."

Perhaps agreement on a federated model (with appropriate safeguards for free speech $)^{72}$ would reduce pressure to fragment the Internet (those pressures are well described in [111]). And, as this author has argued elsewhere $[20,56,72]$, for sure an international agreement on cooperation with respect to security would likely reduce unilateral government surveillance programs and thus reduce the tensions arising from such programs. Indeed, the thrust of the European February 2014 statement [191] would appear to be to propose various international cooperation efforts that could reduce the pressure to fragment the Internet and could help to maintain the current governance arrangements (as usual referred to as "the

\footnotetext{
${ }^{71}$ As Mueller [11] puts the matter: “... open, universal access among all users connected to the Internet, regardless of jurisdiction, is precisely what has made the Internet so valuable". It should be noted, however, that various governments take various measures to stymie such universal access, which, in their view, has some negative consequences.

72 For example based on the principles found at $<$ necessaryandproportionate.org $>$ accessed 10 October 2013, or those outlined by Weber [ 96 section 4.2(b)].
}

multi-stakeholder model"). But of course those governments (and there are many of them) who currently engage in unilateral surveillance are unlikely to agree to any measures that would restrict their programs, and indeed a report commissioned by the head of one such government explicitly calls for continuing its practice of treating non-citizens and non-residents differently, that is, with fewer procedural safeguards for what they refer to as "non-national persons" [95 pp. 32 and 156 ff.]. (For a good summary review of the existing laws that allow such practices in one country, see [120]). Indeed, the US reply [192] to the February 2014 European statement did not mention any of the measures proposed by Europe, except for the globalization of ICANN, which was the least significant of the European proposals.

Further, those private companies who benefit from the current arrangements are likely to encourage their governments to resist any changes (indeed, many companies were heavily involved in WCIT [20]), as one commentator put the matter regarding the concentration of international Internet connections [142]: "If internet servers were truly decentralized ... US ISPs would end up paying considerably more money to their foreign counterparts". But the issue is not just where the servers are located, but where the content is stored, analyzed, and used to generate revenues (e.g. advertising revenues); in this context, see the statements attributed to India [105]. So even decentralizing servers may not be sufficient to address the economic disparities outlined above, to do that might require more invasive measures, such as agreements on how to tax the digital economy [154]. Or requirements that certain types of data not be stored abroad [95 p. 215], or that it not be stored in the USA [221], a move which the US will surely resist, see the explicit statement to that effect in a report to the US President [95 pp. 38, 221, and 223]. How effective such resistance might be is open to question, see for example Brazilian plans to bypass the US for telecommunications traffic and to store data within the country [222-224], and a similar Indian proposal [225]. And a decision by the Swiss Government [226] to use only national suppliers for very important ICT services, and a call by German Prime Minister Merkel to set up a European communications network to avoid US surveillance [227], a virulent call by Russian President Putin for an alternative to the current situation [228].

Major companies whose business model depends on the current situation will of course strenuously object to such developments, going so far as to say that they will "break the Internet" [214]. But whether data localisation would break the Internet depends on what one thinks "the Internet" is supposed to be. Those companies, and the US surveillance apparatus, think it should be a vast repository of personal data that is freely accessible by all for whatever reason $[179,229]$. And indeed data localisation breaks that. But of course many think that "the Internet" is supposed to be something else, namely a tool that allows users to 
communicate what they want, when they want, to whom they want. And that allows users to retain control of their data in accordance with their national laws. In that sense, it is the NSA and companies such as Google that have broken the Internet. So the criticized proposals are in reality merely attempts to try to fix it. It is worth mentioning in this context that all private companies already isolate their internal networks via firewalls and such, so that there are already vast islands that are only partially interconnected.

A cynical observer might conclude that it is unlikely that an international legal framework could be agreed. However, this view does not take into account the economic consequences of the lack of agreement, which could lead to a true fragmentation of the Internet, with a consequential very significant loss of revenue for the companies that are currently the most profitable $[73,95$ p. $212,221,230] .{ }^{73}$ An excellent summary and analysis of this situation is given in [229]. As Powers and Jablonski [3 Chapter 8] put the matter: "....accepting some level of shared internet regulations is a far superior option to an internet splintered along geographical and national boundaries." See also the various citations in [200]. The risk of fragmentation was highlighted in a statement by ISOC [232], but that statement says that the current "open, inclusive standardization and governance approach remains the model least susceptible to abuse", where abuse refers to pervasive surveillance. But in fact it is exactly the current governance approach that has facilitated abusive surveillance, because of its hand-off approach at the international level and the fact that national laws and regulations are enforced nationally. There is an international framework at present: it is a highly liberal framework (but, as noted above, there is some dispute regarding whether it results in competition). If the alternative to a new, possibly less liberal, international framework is a total breakup of the Internet, then the concerned private companies are likely to opt for what is for them the lesser evil and accept a new framework. The failures of WSIS and WCIT to agree such frameworks do not necessarily mean that one could not be agreed in the future.

Nor would such a new framework necessarily be based on the concept of sovereign nation states. As Mueller [11] states: "If we succeed in developing new formulations of rights to govern such [Internet] activities, the most appropriate unit of collective action would not be the nation state." This proposal should be seen in the context of discussions mentioned above regarding transfer of certain powers to non-governmental institutions, the need for

\footnotetext{
${ }^{73}$ In this context, see the call by key companies for reform of government surveillance practices cited by Wyatt and Miller [73]: $<\mathrm{http}: / /$ reformgovernmentsurveillance.com/> accessed 9 December 2013. Note however that that call for reform does not actually call for any changes in current business practices and that it calls for continuation of storage of data in the United States [235]. Subsequently, it appeared that some customers were requiring that data be stored outside of the USA [221].
}

states to take measures to avoid or mitigate extra-territorial effects of their actions, and to avoid or mitigate interfering with the national sovereignty of other states with respect to matters where sovereignty is retained [69]; and regarding the evolving nature of political power and the very concept of sovereignty [ 96 section 1.1]. Or it could be based on the decentralized peer to peer architecture alluded to in [233]. Any proposals along such lines would require formal recognition, at the international level, of what Mueller [11 p. 209] describes as "the truth that there are many transnational communities or polities, created by global electronic communications, whose individual members have their own intrinsic rights to communicate amongst themselves." Of course such a proposal is idealistic, and for sure an utopia at present, but who can say what will come to pass in the future? According to the cited author [11 p. 244]:

“... The idea [behind the creation of ICANN] was to detach coordination and policy from the territorial jurisdiction of national states in order to avoid these [differing national policies] jurisdictional conflicts.

"Ultimately, the Tunis Agenda's attempt to resolve the problem through a hierarchically imposed division of labor between states and the rest of society is both conceptually unsound and impossible to implement".

Whether or not the concept is conceptually unsound is of course a value judgment. Whether it is impossible to implement is difficult to say, because it has never been tried: as noted repeatedly above, the USA has retained its dominant role, so the division of labor foreseen in the Tunis Agenda never came to pass (it is not a coincidence that the first priority issue listed in the Report of the Working Group on Internet Governance (WGIG) was "unilateral control by the United States government" [32 para. 15]). Perhaps the Tunis Agenda proposal was an idealistic and utopian proposal but, again, who can say what will come to pass in the future? It may well be that large private companies attempt to take things into their own hands, for example by implementing encryption measures meant to defeat government surveillance [234], but who can say whether governments will take steps to prevent that [235], despite calls by a US report for the USA to refrain from undermining encryption [ 95 pp. 36 and 216 ff.]?

\subsection{Conclusion}

In any case, there is a need for international agreement on all the issues outlined above. Indeed, a report to the US President called for an agreement among multiple nations for some set of Internet norms [95 p. 223]. However, it must be emphasized that there are persisting strong differences in views of what to agree and even how to discuss it [236, 237]. The issue of freedom to communicate is of course the thorniest issue, so it might be more 
productive to start by addressing the relatively less contentious issues, such as protecting privacy and addressing the asymmetric role of the US government [199]. And it might be productive to discuss such issues in a variety of forums, including the ITU in which, as noted above, it was agreed by consensus to discuss certain specific issues. And, as this author has argued elsewhere $[20,52,56]$, it may be worth considering whether the 2012 ITRs could provide a starting point for new discussions leading to consensus for at least some elements of an international framework. Other possible starting points for such a framework could be national frameworks proposed in Brazil [42] and in South Africa [238] or a proposal for making the root zone file inviolable under international law [239], a "digital bill of rights" [240, 241], or the "platform model" approach to Internet regulation put forward in [155].

Respected security expert Bruce Schneier has stated [242] "The Internet has become essential to our lives, and it has been subverted into a gigantic surveillance platform. The solutions have to be political. The best advice for the average person is to agitate for political change." Indeed, security is unlikely to improve unless its externalities are recognized [57]. Thus, more ambitiously, one might strive for a "constitutionalization" of Internet governance, which is the idea that "a constitution should govern our globalized world, keeping in mind that the form and substance of such a global constitution may have little to do with that of domestic constitutions" [101 p. 57]. Any such "constitutionalization" should take into account the complexities due to global access to information absent global agreements on acceptable limits to such access. Weber [96 section 4.1(b)] suggests that new approaches may be appropriate, with less hierarchical and flatter structures, and he outlines some key elements to take into account (see also [233]).

International frameworks exist, and are not strongly challenged, in other industries, such as civil aviation and maritime commerce. While such frameworks are probably not applicable, per se, to the Internet, there is no reason to think that some other framework would not be applicable. And, with respect to curtailing pervasive surveillance, one might make an analogy to various arms-control treaties, under which nations agree to restrict certain practices [243 p. 12]. Or one might envision "Internet Norms for Cyberspace" such as a prohibition on industrial espionage, a protection of financial services and markets data standard, etc. [95 p. 224]. Or one might envision rules regarding transparency of data collection [75]. Or a general set of rules covering various aspects [172]. Indeed, it may well be that, in the future, governments will focus on appropriate rules regarding the high-level services that are increasingly becoming the most important part of the Internet, and shift their focus away from the lower-levels such as interconnection at the TCP/IP level and current Internet domain names and addresses. ${ }^{74}$ Regarding domain names, they might become less visible (and thus generate less international discussion) if the digital-object architecture proposed by Khan is widely implemented and used [244].

It is perhaps utopian, but this author is of the view that an appropriate international framework would safeguard human rights (including the right to privacy) ${ }^{75}$ and would create a competitive environment under which fair and equitable private contracts can be made. And it is surely realist to speculate that, absent such a framework, more and more governments will engage in pervasive unilateral surveillance, not just of their own citizens, but also of foreign citizens. ${ }^{76}$ A UN Resolution clearly calls for curtailing (or at least limiting) such activities. ${ }^{77}$ This is a useful first step, but no substitute for a binding agreement between states, that is, a treaty. And what institution, other than ITU, could transform itself to provide a forum for negotiating such a global agreement (regarding the transformation of ITU in recent years, see [247])? Would states relinquish to "the multi-stakeholder model" the power to curtail surveillance? And would "the multi-stakeholder model" curtail the power of dominant private companies? Similar questions are posed by Jamart [101 p. 76]. Perhaps the time has come to acknowledge that certain aspects of the Internet are public goods, and must be governed as such [248].

\section{REFERENCES}

[1] Hills, Jill, 2007. Telecommunications and Empire. University of Illinois Press.

[2] Hill, Richard, 2013b. "Internet Governance: The Last Gasp of Colonialism, or Imperialism by Other Means?", in Weber, R. H., Radu, R., and Chenou, J.-M. (eds) The evolution of global Internet policy: new principles and forms of governance in the making?, Schulthess/Springer.

[3] Powers, Shawn and Jablonski, Michael, 2014. The Real Cyber War: The Political Economy of Internet Freedom, University of Illinois Press

[4] Kim, Jino W., 2005. "Economic Theory and Practices: Telecommunication Policy and Regulation for Competition", ITU

\footnotetext{
${ }^{74}$ In this context, see $[138,139,245]$.

75 In this context, it must be noted that in its 10 February 2014 submission to the ITU CWG-Internet, the United States takes the view that there should not be any international harmonization of privacy laws; on the contrary, each country should recognize that there are different approaches to privacy (Information Document 33 of the Fourth Meeting of CWG-Internet). It remains to be seen whether this view will be acceptable to countries that have stronger data privacy laws than does the US.

${ }_{76}$ A fictional account of the dystopia that might arise if such trends continue is presented in [246].

77 Resolution A/RES/68/167, The right to privacy in the digital age $<$ http://www.un.org/en/ga/search/view doc.asp?symbol=A/RES/68/167>
} 
$<$ http://www.itu.int/ITU-D/treg/Events/Seminars/2005/Tha iland/Reference\%20Material/Background\%20Paper\%20$\% 20$ Economic $\% 20$ Theory\%20and $\% 20$ Practices.pdf $>$ accessed 23 August 2013.

[5] Baran, Paul, 1967. "The Future Computer Utility", National Affairs, vol. 8, p. 75

$<$ http://www.nationalaffairs.com/public interest/detail/thefuture-computer-utility $>$ accessed 21 November 2013.

[6] History of Internet, 2013.

$<$ http://en.wikipedia.org/wiki/History of Internet> accessed 5 June 2013.

[7] Schiller, Dan, 2014b. "Rosa Luxemburg's Internet? For a Political Economy of State Mobilization and the Movement of Accumulation in Cyberspace", International Journal of Communication, vol. 8, p. 335

$<$ http://ijoc.org/index.php/ijoc/article/view/2045/1076>.

[8] Hannemyr, Gisle, 2003. "The Internet as Hyperbole", The Information Society, vol. 19 no. 2, p. 111 $<$ http://hannemyr.com/en/diff.php $>$ accessed 10 November 2013.

[9] Hill, Richard, 1997. "Electronic Commerce, the World Wide Web, Minitel, and EDI", EDI Forum, vol. 9 no. 2, p. 89; and The Information Society, vol. 13 no. 1, Jan-Mar 1997, p. 33.

[10] Goldsmith, Jack and $\mathrm{Wu}$, Tim, 2006. Who Controls the Internet: Illusions of a Borderless World, Oxford University Press.

[11] Mueller, Milton, 2010. Networks and States: The Global Politics of Internet Governance, MIT Press.

[12] McKinnon, Rebecca, 2012. Consent of the Networked: The Worldwide Struggle for Internet Freedom, Basic Books.

[13] Hathaway, Melissa, 2014. "Connected Choices: How the Internet is Challenging Sovereign Decisions", American Foreign Policy Interests, vol. 36, no. 1, p. 300 $<$ http://belfercenter.ksg.harvard.edu/publication/24689/con nected_choices.html>

[14] Mueller, Milton, 2017. Will the Internet Fragment? Sovereignty, Globalization and Cyberspace, polity

[15] Mueller, Milton, 2013. "The Core Internet Institutions Abandon the US Government", Internet Governance Project, 11 October 2013

$<$ http://www.internetgovernance.org/2013/10/11/the-core-i nternet-institutions-abandon-the-us-government/> accessed 10 November 2013.

[16] Rousseff, Dilma, President of Brazil, 2013. "Statement at the Opening of the General Debate of the $68^{\text {th }}$ Session of the United Nations General Assembly", United Nations, 24 September 2013

$<$ http://gadebate.un.org/sites/default/files/gastatements/68/ BR en.pdf $>$ accessed 4 October 2013.

[17] Harris, Frederick, 2013a. "Rewiring Internet Governance: Step 1 is about ICANN (Part 1)", CircleID, 26 November 2013

$<\mathrm{http}: / /$ www.circleid.com/posts/20131126_rewiring_intern et_governance_step_one_is_about_icann_part_1/> accessed 8 January 2014 .

[18] Hill, Richard, 2016. "Internet governance, multi-stakeholder models, and the IANA transition: shining example or dark side?", Journal of Cyber Policy, Vol. 1, No. 2

[19] IAHC, 2013. Wikipedia <http://en.wikipedia.org/wiki/IAHC> accessed 5 June 2013.

[20] Hill, Richard, 2013. The New International Telecommunication Regulations and the Internet: $A$ Commentary and Legislative History, Schulthess/Springer $<$ http://www.springer.com/law/international/book/978-3-6 42-45415-8>.

[21] Hill, Richard, 2014. "The Internet, its governance, and the multi-stakeholder model". Info, Vol. 16 No 2

[22] Kahn, Robert. E. and Cerf, Vint G., 1999. "What Is The Internet (And What Makes It Work)", December 1999 $<\mathrm{http}$ //www.cnri.reston.va.us/what_is_internet.html> accessed 10 June 2013.

[23] European Parliament and Council of the European Union, 2002. Directive 2002/21/EC on a common regulatory framework for electronic communications networks and services, 7 March 2002

$<$ http://eur-lex.europa.eu/LexUriServ/LexUriServ.do?uri= OJ:L:2002:108:0033:0050:EN:PDF> accessed 9 November 2013.

[24] ITU, 2013a. Numbering Resources $<$ http://www.itu.int/en/ITU-T/inr/Pages/default.aspx> accessed 15 March 2013.

[25] Internet Assigned Names Authority, 2013. Wikipedia $<$ http://en.wikipedia.org/wiki/Internet_Assigned_Numbers _Authority $>$ accessed 5 June 2013.

[26] Mueller, Milton, 1999. "ICANN and Internet Governance: sorting through the debris of 'self-regulation', Info, vol. 1 no. 6 , p. 497

$<\mathrm{http}$ //www.icannwatch.org/archive/mueller_icann_and_i nternet_governance.pdf $>$.

[27] Froomkin, Michael, 2000. "Wrong Turn in Cyberspace: Using ICANN to Root around the APA and the Constitution", Duke Law Journal, vol. 50 p. 17 $<$ http://osaka.law.miami.edu/ froomkin/articles/icann.pdf $>$ accessed 14 November 2013.

[28] Mueller, Milton, 2002. Ruling the Root: Internet Governance and the Taming of Cyberspace. MIT Press.

[29] Weber, Rolf. H, 2009. "Internet Corporation for Assigned Names and Numbers", in Christian Tietje and Alan Brouder Alan (Eds.). Handbook of Transnational Economic Governance Regimes. Martinus Nijhoff, pp. 612-614.

[30] Kruger, Lennard G., 2013. Internet Governance and the Domain Name System: Issues for Congress, Congressional Research Service, 13 April 2013

$<$ http://www.fas.org/sgp/crs/misc/R42351.pdf > accessed 6 October 2013.

[31] Chenou, Jean-Marie and Radu, Roxana, 2013. "Global Internet Policy: a Fifteen-Year Long Debate”, in Weber, R. H., Radu, R., and Chenou, J.-M. (eds), The evolution of global Internet policy: new principles and forms of governance in the making?, Schulthess/Springer.

[32] Working Group on Internet Governance, 2005. Report, 3 August 2005

$<$ http://www.itu.int/wsis/documents/doc_multi.asp?lang=e n\&id $=1695 \mid 0>$ accessed 20 November $2 \overline{0} 13$. 
[33] Kurbalija, Jovan, 2012. An Introduction to Internet Governance, fifth edition, Diplo Foundation.

[34] Reidenberg, J., 2005. "Technology and Internet Jurisdiction", University of Pennsylvania Law Review, vol. 153, p. 1951.

[35] Wright, Benjamin. 1991. The Law of Electronic Commerce, Little, Brown and Company.

[36] Gringras, Clive, 1997. The Laws of the Internet, Butterworths.

[37] Reed, Chris, 2012. Making Laws for Cyberspace, Oxford University Press.

[38] Maher, K., 2012. "The New Westphalian Web", Foreign Policy, 25 February 2012

$<$ http://www.foreignpolicy.com/articles/2013/02/25/the ne w_westphalian_web?page $=0,0>$ accessed 21 May 2013 .

[39] Feld, H., 2013. "Testimony", 5 February 2013 Hearing: Fighting for Internet Freedom, Dubai and Beyond, U.S. House of Representatives Committee on Energy and Commerce's Subcommittee on Communications and Technology

$<$ http://docs.house.gov/meetings/IF/IF16/20130205/10022

1/HHRG-113-IF16-Wstate-FeldH-20130205.pdf> accessed 15 May 2013.

[40] Mueller, Milton, 2013a. "WTF? WTPF! The continuing battle over Internet governance principles", The Technology Liberation Front, $23 \quad$ April 2013 $<$ http://techliberation.com/2013/04/23/wtf-wtpf-the-contin uing-battle-over-internet-governance-principles/> accessed 21 May 2013.

[41] Bronsword, R., 2012. "The shaping of our on-line worlds: getting the regulatory environment right" International Journal of Law and Information Technology, vol. 20, p. 272.

[42] Ermert, Monika, 2013b. "Desperate Final Stretch for the 'Marco Civil do Brasil'", Intellectual Property Watch, 14 November 2013

$<$ http://www.ip-watch.org/2013/11/14/desperate-final-stret ch-for-the-marco-civil-do-brasil/ $>$ accessed 9 December 2013.

[43] Housley, Russ, 2013. "IETF88 Technical Plenary Hums", E-Mail, 6 November 2013

$<$ https://www.ietf.org/mail-archive/web/ietf/current/msg83 857.html $>$ accessed 9 November 2013.

[44] Nair, Abhilash, and Griffin, James, 2013. "The regulation of online extreme pornography: purposive teleology (in)action", International Journal of Law and Information Technology, vol. 21 no. 4, p. 329.

[45] Liddicoat, J. and Doria, A., 2012. "Human Rights and Internet Protocols: Comparing Processes and Principles", Internet Society, December 2012

$<\mathrm{http}$ ://www.internetsociety.org/doc/human-rights-and-int ernet-protocols-comparing-processes-and-principles> accessed 21 May 2013.

[46] Bommelaer, Constance, 2014. "Internet Governance Observations and Recommendations from Members of the Internet Technical Community", submission to NETMundial meeting, 23-24 April $2014<$ $\mathrm{http}: / /$ content.netmundial.br/contribution/internet-governan ce-observations-and-recommendations-from-members-of- $t$ he-internet-technical-community/235> accessed 11 March 2014.

[47] Fernàndez González, Juan Alonso, 2011. "Economic sustainability of international telecommunication networks". Info, Vol. 13, No.. 11, p. 6.

[48] ITU, 2013. International Internet Connectivity $<$ http://www.itu.int/ITU-T/studygroups/com03/iic/index.ht $\mathrm{ml}>$ accessed 15 March 2013.

[49] AT Kearney, 2010. A Viable Future Model for the Internet $<$ http://www.atkearney.com/index.php/Publications/a-viabl e-future-model-for-the-internet.html $>$ accessed 16 July 2013.

[50] Weller, David and Woodcock, Bill, 2013. "Internet Traffic Exchange: Market Developments and Policy Challenges". OECD Digital Economy Papers, No. 207, OECD Publishing <http://dx.doi.org/10.1787/5k918gpt130q-en>.

[51] MacKie-Mason, Jeffrey K. and Varian, Hal R., 1996. "Some Economics of the Internet", in Sichel, W. (ed) Networks, Infrastructure and the New Task for Regulation, University of Michigan Press

$<$ http://deepblue.lib.umich.edu/bitstream/handle/2027.42/5 0461/Economics of Internet.pdf?sequence $=1>$ accessed 26 January 2014.

[52] Hill, Richard, 2013a. "WCIT: Failure or success, impasse or way forward?" International Journal of Law and Information Technology, vol. 21 no. 3, p. 313, DOI:10.1093/ijlit/eat008

$<$ http://ijlit.oxfordjournals.org/content/21/3/313>.

[53] Talbot, D., 2006. "The Internet is broken" MIT Technology Review, December 2005/January 2006, p. 62, < http://www.technologyreview.com/news/405318/the-intern et-is-broken/> accessed 20 May 2013.

[54] Deibert, Ronald J., 2013. Black Code: Inside the Battle for Cyberspace, Signal (McClelland and Stewart).

[55] Brunton, Finn, 2013. Spam: A Shadow History of the Internet, MIT Press.

[56] Hill, Richard, and Powers, Shawn. 2013. "Cybersecurity and spam: WCIT and the Future", World Cyberspace Cooperation Summit IV, 5-6 November 2013, Silicon Valley, California, USA

$<$ http://cybersummit.info/sites/cybersummit.info/files/EWI \%20final\%20rev2\%20clean.pdf> accessed 18 March 2014.

[57] Schneier, Bruce, 2007. "Information Security and Externalities", Schneier on Security, January 2007 $<$ https://www.schneier.com/essay-150.html $>$ accessed 14 April 2014.

[58] Williams, Lauren, 2014. "Microsoft Kills Windows XP Security Updates, Turning Millions of Computers into Hacker Playgrounds", ThinkProgress, 8 April 2014 $<$ http://thinkprogress.org/economy/2014/04/08/3424239/w indows-xp-doomsday/> accessed 14 April 2014.

[59] Tworek, Heidi, 2017. "Microsoft is Right: We Need a Digital Geneva Convention", Wired, 9 May 2017 $<$ https://www.wired.com/2017/05/microsoft-right-need-dig ital-geneva-convention/> accessed 10 December 2017.

[60] AlQurashi, Mansour, 2013. Contribution to ITU public 
consultation on International Internet-related public policy issues, 10 October $2013<\mathrm{http} / /$ www.itu.int/en/council/Pa ges/display.aspx?ListItemID $=80>$ accessed 25 October 2013.

[61] Musiani, Francesca, and Pohle, Julia, 2014. "NETMundial: only a landmark event if 'Digital Cold War' rhetoric abandoned", Internet Policy Review, 27 March 2014 $<$ http://policyreview.info/articles/analysis/netmundial-only -landmark-event-if-digital-cold-war-rhetoric-abandoned> accessed 29 March 2014.

[62] Drake, William, 2011. "Multistakeholderims: Internal Limitations and External Limits", in MIND: Multistakeholder Internet Dialog, Co:llaboraty Discussion Paper Series No. 2, Internet Policymaking, 68-72 $<$ http://www.academia.edu/1998240/Drake William_J. 20 11. Multistakeholderism Internal Limitations and Exter nal_Limits. In MIND Multistakeholder Internet_Dialog Co_llaboratory_Discussion_Paper_Series_No.2_-_nternet Policymaking 68 -72 Berlin Co llaboratory $>-\bar{a}$ accessed $2 \overline{9}$ March 2014

[63] Brown, D. et. al., 2013. "Input to the World Telecommunication/ICT Policy Forum (WTPF13)", information document 6 submitted to the World Telecommunication Policy Forum $<$ http://www.itu.int/md/S13-WTPF13-INF-0006/en> accessed 15 May 2013.

[64] Dori, Avria, 2013. "Use [and Abuse] of Multistakeholderism in the Internet", in Weber, R. H., Radu, R., and Chenou, J.-M. (eds) The evolution of global Internet policy: new principles and forms of governance in the making?, Schulthess/Springer.

[65] Utopia, 2013. Wikipedia $<$ http://en.wikipedia.org/wiki/Utopia $>$ accessed 7 November 2013.

[66] Dystopia, 2013. Wikipedia $<$ http://en.wikipedia.org/wiki/Dystopia $>$ accessed November 2013.

[67] Realpolitik, 2013. Wikipedia $<$ http://en.wikipedia.org/wiki/Realpolitik $>$ accessed 15 October 2013.

[68] Morozov, Evgeny, 2011. The Net Delusion: The Dark Side of Internet Freedom, Public Affairs.

[69] Weber, Rolf H., 2010. "New Sovereignty Concepts in the Age of Internet?", Journal of Internet Law, August, p. 16.

[70] Weber, Rolf. H., and Heinrich, Ulrike I., 2011. "IP Address Allocation through the Lens of Public Goods and Scarce Resource Theories". Scripted, Vol. 8, No. 1, p. 83.

[71] Raymond, M. and Smith, G., 2013. "Reimagining the Internet: The Need for a High-level Strategic Vision for Internet Governance," Centre for International Governance Innovation, Internet Governance Papers, Paper No. 1, July 2013

$<\mathrm{http}$ //www.cigionline.org/sites/default/files/no1_4.pdf $>$ accessed 10 August 2013.

[72] EPFL Congress on Privacy and Surveillance, 2013. Ecole Fédéral Polytechnique de Lausanne, 30 September 2013 $<$ http://ic.epfl.ch/privacy-surveillance $>$ accessed 4 October 2013.
[73] Wyatt, Edward and Miller, Claire C., 2013. "Tech Giants Issue Call for Limits on Government Surveillance of Users", The New York Times, 9 December 2013 $<$ http://www.nytimes.com/2013/12/09/technology/tech-gia nts-issue-call-for-limits-on-government-surveillance-of-us ers.html?hp\&_r=1\&> accessed 10 December 2013.

[74] McChesney, Robert W., 2013. Digital Disconnect: How Capitalism is Turning the Internet Against Democracy, The New Press.

[75] Hundt, Reed E., 2014. "Making No Secrets About It", I/S: A Journal of Law and Policy for the Information Society, forthcoming, preliminary draft

$<$ http://moritzlaw.osu.edu/students/groups/is/online-nsa-sy mposium/> accessed 26 December 2013.

[76] Marwick, Alice E., 2014. "How Your Data Are Being Deeply Mined", The New York Review of Books, 9 January 2014

$<$ http://www.nybooks.com/articles/archives/2014/jan/09/h ow-your-data-are-being-deeply-mined/> accessed 11 January 2014.

[77] Moglen, Eben, 2013. Snowden and the Future: Part III; The Union, May It Be Preserved, lecture at Columbia Law School, $13 \quad$ November October 2013 $<$ http://snowdenandthefuture.info/snowdenandthefuture-un ionpreserved.pdf $>$ accessed 15 December 2013.

[78] Shipman Wentworth, S., 2013. "Testimony”, 5 February 2013 Hearing: Fighting for Internet Freedom, Dubai and Beyond, U.S. House of Representatives Committee on Energy and Commerce's Subcommittee on Communications and Technology

$<$ http://docs.house.gov/meetings/IF/IF16/20130205/10022 1/HHRG-113-IF16-Wstate-ShipmanWentworthS-2013020 5.pdf $>$ accessed 15 May 2013.

[79] De Nardis, L., and Raymond, M. (2013), “Thinking Clearly about Multistakeholder Internet Governance", Eighth Annual GigaNet Symposium, Bali Indonesia, 21 October 2013.

$<$ http://papers.ssrn.com/sol3/papers.cfm?abstract_id=2354 $377>$

[80] Hoffman, J. 2016. "Multi-stakeholderism in Internet governance: putting a fiction into practice", Journal of Cyber Policy, Vol. 1 No 1, pp. 29-49 $<$ http://www.tandfonline.com/doi/pdf/10.1080/23738871.2 016.1158303 $>$ accessed 28 May 2016

[81] Watkins, Thayer, 2013. "Corporatism", The Economic System of Corporatism $<$ http://www.sjsu.edu/faculty/watkins/corporatism.htm> accessed 11 November 2013.

[82] Mueller, Milton, 2013c. “Are We Re-Booting All Internet Governance" (Or Just Releasing A Lot of Hot Air?), Internet Governance Project, 20 October 2013 $<$ http://www.internetgovernance.org/2013/10/20/plans-forinternet-commission-on-internet-cooperation-revealed/> accessed 25 October 2013.

[83] Corporatism, 2013. Wikipedia $<$ http://en.wikipedia.org/wiki/Corporatism> accessed 10 October 2013.

[84] Berger, Suzanne (ed.), 1983. Organizing Interests in Western Europe: Pluralism, Corporatism, and the 
Transformation of Politics, Cambridge Studies in Modern Political Economies, Cambridge University Press.

[85] Malcomson, S. 2016. Splinternet: How Geopolitics and Commerce are Fragmenting the World Wide Web. New York: OR Books

[86] Wu, Tim, 2010. The Master Switch: The Rise and Fall of Information Empires, Knopf.

[87] Foster, Bellamy and McChesney, Robert W., 2011. "The Internet's Unholy Marriage to Capitalism", Monthly

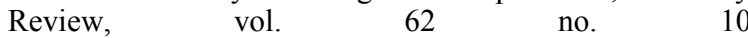
$<$ http://monthlyreview.org/2011/03/01/the-internets-unhol y-marriage-to-capitalism> accessed 3 December 2013.

[88] Gurstein, Michael, 2013. "Multistakeholderism vs. Democracy: My Adventures in 'Stakeholderland", Gurstein's Community Informatics, 20 March 2013 $<$ http://gurstein.wordpress.com/2013/03/20/multistakehold erism-vs-democracy-my-adventures-in-stakeholderland/> accessed 21 November 2013.

[89] Chenou, Jean-Marie and Radu, Roxana, 2013a. "From Nested Dilemmas to Democratinc Internet Governance", in Weber, R. H., Radu, R., and Chenou, J.-M. (eds), The evolution of global Internet policy: new principles and forms of governance in the making?, Schulthess/Springer.

[90] Bauer, Johannes M, and Latzer, Michal (eds), 2016. Handbook on the Economics of the Internet, Edward Elgar

[91] Schmidt, Andreas, 2013. "Open Security: Contributions of Networked Approaches to the Challenge of Democratic Internet Security Governance", in Weber, R. H., Radu, R., and Chenou, J.-M. (eds), The evolution of global Internet policy: new principles and forms of governance in the making?, Schulthess/Springer.

[92] Cornwall, Andrea, 2008. 'Unpacking 'Participation', models, meanings and practices", Community Development Journal, vol. 43 no. 3, p. 269 $<$ http://cdj.oxfordjournals.org/content/43/3/269.abstract $>$ accessed 19 December 2013.

[93] Harris, Frederick, 2013b. "Rewiring Internet Governance: U.S. Government Will Likely Be Forced to Jettison ICANN (Part 3)", CircleID, 17 December 2013 $<$ http://www.circleid.com/posts/20131217 rewiring intern et_governance_us_likely_be_forced_to_jettison_icann/> accessed 8 January 2014.

[94] Mueller, Milton, 2013b. “Get Real(ist): Don't Confuse NSA Regulation With Internet Regulation”, Internet Governance Project, 26 October 2013

$<$ http://www.internetgovernance.org/2013/10/26/get-realist -dont-confuse-nsa-regulation-with-internet-regulation/> accessed 30 October 2013.

[95] Clarke, Richard A. et al., 2013. Liberty and Security in a Changing World: Report and Recommendations of the President's Review Group on Intelligence and Communication Technologies, US White House, 12 December 2013

$<$ http://www.whitehouse.gov/sites/default/files/docs/201312-12_rg_final_report.pdf $>$ accessed 23 December 2013.

[96] Weber, Rolf H., 2013a. "Visions of Political Power: Treaty Making and Multistakeholder Understanding”, in Weber, R. H., Radu, R., and Chenou, J.-M. (eds) The evolution of global Internet policy: new principles and forms of governance in the making?, Schulthess/Springer.

[97] Sutherland, Ewan, 2014. "Corruption and internet governance", Info, vol. 16 no. 2, p. 1.

[98] Corwin, Philip, 2014. "ICANN's Uncertain State: 2014", CircleID, 21 February 2014

$<$ http://www.circleid.com/posts/20140221 icanns_uncertai n_state_2014> 23 February 2014.

[99] Ontoyin, Simon et al. 2014. "NETmundial submission: Roadmap for the Further Evolution of the Internet Governance Ecosystem - ICANN", Best Bits $<$ http://bestbits.net/netmundial-icann/> accessed 5 March 2014.

[100] Ermert, Monika, 2011. "Proposal For New UN Internet Governance Body Meets Resistance", Intellectual Property Watch, 3 October 2011

$<$ http://www.ip-watch.org/2011/10/03/proposal-for-new-u n-internet-governance-body-meets-resistance/ $>$ accessed 27 November 2013.

[101] Jamart, Anne-Claire, 2013. "Internet Freedom and the Constitutionalization of Internet Governance", in Weber, R. H., Radu, R., and Chenou, J.-M. (eds) The evolution of global Internet policy: new principles and forms of governance in the making?, Schulthess/Springer.

[102] Savage, Charlie, Wyatt, Edward, and Baker, Peter, 2013. "U.S. Confirms that it Gathers Online Data Overseas". The New York Times, 6 June 2013

$<$ http://www.nytimes.com/2013/06/07/us/nsa-verizon-calls .html?_r=0 $>$ accessed 8 June 2013.

[103] Taylor, Astra, 2014. The People's Platform: Taking Back Power and Culture in the Digital Age, Random House.

[104] Gurstein, Michael, 2014. "The Multistakeholder Model, Neo-liberalism and Global (Internet) Governance", Gurstein's Community Informatics, 26 March 2014 $<$ http://gurstein.wordpress.com/2014/03/26/the-multistake holder-model-neo-liberalism-and-global-internet-governan ce/> accessed 27 March 2014.

[105] Joshi, Sandeep, 2013. "India to push for freeing Internet from US control", The Hindu, 7 December 2013 $<$ http://www.thehindu.com/sci-tech/technology/internet/in dia-to-push-for-freeing-internet-from-us-control/article543 4095.ece?homepage=true $>$ accessed 10 December 2013.

[106] Chaturvedi, Subia, 2014. "For an unfettered Internet", The Hindu, 18 February 2014

$<$ http://www.thehindu.com/opinion/lead/for-an-unfetteredinternet/article5699615.ece> accessed 18 February 2014.

[107] Ghali, Boutrous Boutros and Gosovic, Branisav, 2011. Global Leadership and Global Systemic Issues: South, North and the United Nations in a $21^{\text {st }}$ Century World, Development Alternatives Global

$<$ http://www.daglobal.org/paper-3.aspx $>$ accessed 27 November 2013.

[108] Sogge, David, 2014. "Corporate crowding into the tents of global governance", Transnational Institute, 24 January $2014<$ http://www.tni.org/article/not-everybodys-business> accessed 8 February 2014.

[109] New, William, 2013a. "A Question of Balance in IP Rights 
in South Africa", Intellectual Property Watch, 21 November 2013

$<$ http://www.ip-watch.org/2013/11/21/a-question-of-balan ce-in-ip-rights-in-south-africa-2/> accessed 25 November 2013.

[110] New, William, 2013b. "US Chamber Event To Rally Support For Trade Deals, Patent Litigation Bill”, Intellectual Property Watch, 7 November $2013<>$ accessed 25 November 2013.

[111] Harris, Frederick, 2014. "Rewiring Internet Governance: Summing Up ICANN Policy Walking Backward Into the Future (Part 4)", CircleID, 2 January $2014<$ http://www.circleid.com/posts/20140102_rewiring_interne $\mathrm{t}$ governance summing icann policy walking backward/> accessed 8 January 2014.

[112] US Bureau of Economic and Business Affairs, 2014. U.S Government Submission to NETmundial on Internet Governance, 24 February 2014

$<$ http://www.state.gov/e/eb/rls/prsrl/2014/221946.htm> accessed 25 February 2014

[113] Plaum, C., 2012. "Globalization of Law Enforcement: A Study of Trans-National Public-Private Partnerships Against Intellectual Property Crimes, Doctoral Thesis, University of Bremen, p. 230

$<$ http://elib.suub.uni-bremen.de/edocs/00103026-1.pdf $>$;a summary can be found in Plaum, C. "Global Public-Private Partnerships Against IP Crimes: How Interpol Avoided the Failures of WCO and WHO”, Intellectual Property Watch, 24 April 2013

$<$ http://www.ip-watch.org/2013/04/24/global-public-privat e-partnerships-against-ip-crimes-how-interpol-avoided-the -failures-of-wco-and-who/> accessed 15 May 2013.

[114] Corporate Europe Observatory, 2013. Regulation, none of our business?, Corporate Europe Observatory, 16 December 2013

$<$ http://corporateeurope.org/publications/regulation-none-o ur-business $>$ accessed 17 December 2013.

[115] Doria, Avri, 2014. "Multistakeholder model as a form of democracy", submission to NETMundial meeting, 23-24 April 2014

$<$ http://content.netmundial.br/contribution/multstakeholder -model-as-a-form-of-democracy/117> accessed 6 March 2014.

[116] Dourado, Eli, 2014. "Taking Consent Seriously", submission to NETMundial meeting, 23-24 April $2014<$ http://content.netmundial.br/contribution/taking-consent-se riously/170> accessed 9 March 2014.

[117] Saez, Catherine, 2013. "US Defender Of Internet Freedom, Keen On Protecting IP Rights”. Intellectual Property Watch, 8 March 2013

$<$ http://www.ip-watch.org/2013/03/08/us-as-defender-of-in ternet-freedom-keen-on-protecting-ip-rights $>$ accessed 15 June 2013.

[118] Bowden, Casper, 2013. "The US National Security Agency (NSA) surveillance programmes (PRISM) and Foreign Intelligence Surveillance Act (FISA) activities and their impact on EU citizens' fundamental rights", Note for the European Parliament

$<$ http://www.europarl.europa.eu/meetdocs/2009_2014/doc uments/libe/dv/briefingnote/briefingnote en.p $\overline{\mathrm{df}}>$ accessed 23 September $201 \overline{3}$.
[119] US National Security Agency, 2013. The National Security Agency: Missions, Authorities, Oversight and Partnerships, 9 August 2013

$<$ http://www.nsa.gov/public_info/_files/speeches_testimon ies/2013_08_09_the_nsa_story.pdf $>$ accessed $1 \overline{3}$ August 2013.

[120] Shane, Peter M., 2014. "The NSA and the Legal Regime for Foreign Intelligence Surveillance", I/S: A Journal of Law and Policy for the Information Society, forthcoming, preliminary draft

$<$ http://moritzlaw.osu.edu/students/groups/is/online-nsa-sy mposium/> accessed 26 December 2013.

[121] New, William, 2013. "Wikileaks's Release of TPP Chapter on IP Blows Open Secret Trade Negotiation", Intellectual Property Watch, 13 November 2013

$<$ http://www.ip-watch.org/2013/11/13/wikileaks-release-of -tpp-chapter-on-ip-blows-open-secret-trade-negotiation/> accessed 14 November 2013.

[122] Kaminski, Margot, 2013. "Capture, sunlight, and the TPP leak", Concurring Opinions, 14 November 2013 $<$ http://www.concurringopinions.com/archives/2013/11/ca pture-sunlight-and-the-tpp-leak.html\# $>$ accessed 16 November 2013.

[123] Larsson, Stefan, 2013. "Metaphors, law and digital phenomena: the Swedish pirate bay court case", International Journal of Law and Information Technology, vol. 21 no. 4 , p. 354.

[124] Hill, Richard, 2014a. "Machiavelli, Huxley and Internet governance", Newsclick, 18 February 2014 $<$ http://newsclick.in/international/machiavelli-huxley-and-i nternet-governance $>$ accessed 19 February 2014.

[125] Simonite, Tom, 2014. "For the Wary, an Alternative to Trusting the Cloud", MIT Technology Review, vol. 116 no. 2, p. 15 .

[126] Ruhe, Lauren and Sundararajan, Arun, 2014. "Digital access, political networks and the diffusion of democracy", Social Networks, vol. 36, p. 40

$<$ http://www.sciencedirect.com/science/article/pii/S037887 $3312000524>$.

[127] Strickling, Lawrence, 2012. Address at the Columbia Institute for Tele-Information (CITI) and IDATE, 24 September 2012

$<$ http://www.ntia.doc.gov/speechtestimony/2012/remarksassistant-secretary-strickling-columbia-institute-tele-infor mation> accessed 8 April 2014.

[128] Souter, David, 2012. “Assessing National Internet Governance Arrangements: A framework for comparative assessment", Internet Society

$<\mathrm{http}$ //www.internetsociety.org/assessing-national-interne t-governance-arrangements $>$ accessed 20 February 2014

[129] Steck, Christoph, 2014. "Contribution of Telefonica to NETMundial”, submission to NETMundial meeting, 23-24 April 2014

$<$ http://content.netmundial.br/contribution/contribution-oftelefonica-to-netmundial/143> accessed 13 March 2014.

[130]Reich, Robert B, 2008. Supercapitalism: The Transformation of Business, Democracy, and Everyday Life, Vintage. 
[131] Schiller, Dan, 2014. Digital Depression: Information Technology and Economic Crisis, University of Illinois Press.

[132] Shaw, Donny, 2013. "Intel Contractors Give Millions to Lawmakers Overseeing Government Surveillance", MapLight, 7 December 2013

$<$ http://maplight.org/content/73373> accessed 15 December 2013.

[133] Werth, Barry, 2013. "A Tale of Two Drugs", MIT Technology Review, vol. 116 no. 6, p. 58.

[134] Huws, Ursula, 2012. "Crisis as Capitalist Opportunity: new accumulation through public service commodification," in Leo Panitch, Greg Albo and Vivek Chibber (eds), The Crisis and the Left, Socialist Register 2012/Merlin Press, 2011: 64-84. An earlier version is available at $<$ http://socialistregister.com/index.php/srv/article/view/156 46> accessed 18 November 2013.

[135] Last mile, 2013. Wikipedia $<$ http://en.wikipedia.org/wiki/Last_mile $>$ accessed 22 November 2013.

[136] Natural Monopoly, 2013. Wikipedia <> accessed 21 November 2013.

[137] Crawford, Susan, 2013. Captive Audience: The Telecom Industry and Monopoly in the New Guilded Age. Yale University Press. A summary is available at $<$ http://business.time.com/2013/01/09/is-broadband-intern et-acces-a-public-utility/?goback=\%2Egde_65453_membe r_204153607>.

[138] Kohl, Uta, 2013. "Google: the rise and rise of online intermediaries in the governance of the Internet and beyond (Part 2)". International Journal of Law and Information Technology, Vol. 21, No. 2, p. 187.

[139] Mac Síthigh, Daithi, 2013. "App law within: rights and regulation in the smartphone age". International Journal of Law and Information Technology, Vol. 21, No. 2, p. 154.

[140] Kopstein, Joshua, 2013. "The Mission to Decentralize the Internet", The New Yorker, 13 December 2013 $<$ http://www.newyorker.com/online/blogs/elements/2013/1 2/the-mission-to-decentralize-the-internet.html $>$ accessed 15 December 2013.

[141] Marwick, Alice E., 2013. Status Update: Celebrity, Publicity, and Branding in the Social Media Age, Yale University Press.

[142] Hruska, Joel, 2012. "FCC fires FUD at the idea of a UN-controlled internet”, ExtremeTech, 23 February 2012 $<$ http://www.extremetech.com/computing/119481-fcc-fires -fud-at-the-idea-of-a-un-controlled-internet $>$ accessed 15 June 2013.

[143] Muller, Jerry Z., 2002. The Mind and the Market. Alfred A. Knopf.

[144] Webb, Malcolm, 2012. "Net neutrality: A regulatory perspective", ITU Global Symposium for Regulators discussion paper, October $2012<$ http://www.itu.int/ITU-D/treg/Events/Seminars/GSR/GSR 12/documents/GSR12_Webb_NetNeutrality_1.pdf> accessed 20 November 2013.

[145] Net neutrality in the United States, 2013. Wikipedia
$<$ http://en.wikipedia.org/wiki/Net neutrality in the Unite d_States $>$ accessed 21 November 2013.

[146] Public good, 2013. Wikipedia

$<$ http://en.wikipedia.org/wiki/Public good $>$ accessed 21 November 2013.

[147] Weber, Rolf H., 2013. "The legitimacy and accountability of the internet's governing institutions", in Ian Brown (ed.), Research handbook on governance of the internet, Elgar/Northampton, p. 101.

[148] ITU Secretary-General, 2013. Report for the Fifth World Telecommunication/Information and Communication Technology Policy Forum 2013, ITU, 15 March 2013 $<$ http://www.itu.int/md/S13-WTPF13-C-0003/en>.

[149] ITU, 2013c. Study on International Internet Connectivity in Sub-Saharan Africa, ITU, March 2013 $<$ http://www.itu.int/en/ITU-D/Regulatory-Market/Docume nts/IIC_Africa_Final-en.pdf> accessed 20 November 2013.

[150] ITU, 2013d. Study on International Internet Connectivity: Focus on Internet Connectivity in Latin America and the Caribbean, ITU, March 2013

$<$ http://www.itu.int/en/ITU-D/Regulatory-Market/Docume nts/International\%20Internet $\% 20$ Connectivity $\% 20$ in $\% 20 \mathrm{~L}$ atin\%20America\%20and\%20the\%20Caribbean.pdf $>$ accessed 20 November 2013.

[151] Abraham, Ruben, 2007. "Mobile Phones and Economic Development: Evidence from the Fishing Industry in India", Information Technologies and International Development, vol. 4 no. 2 , p. $5<$ http://www.itidjournal.org/index.php/iti d/article/download/241/111> accessed 3 December 2013.

[152] Sullivan, Kevin, 2006. "For India's Traditional Fishermen, Cellphones Deliver a Sea Change", The Washington Post, 15 October 2006

$<$ http://www.washingtonpost.com/wp-dyn/content/article/2 006/10/14/AR2006101400342.html> accessed 3 December 2013.

[153]ITU, 2013e. The Mobile Money Revolution, ITU-T Technology Watch Report

$<$ http://www.itu.int/en/ITU-T/techwatch/Pages/mobile-mo ney-standards.aspx $>$ accessed 3 December 2013.

[154] G20 Leaders, 2013. "Tax Annex to the St. Petersburg Declaration", G20, 6 September 2013 $<$ http://www.g20.org/news/20130906/782776427.html> accessed 11 October 2013.

[155] Claffy, KC and Clark, Richard C., 2013. "Platform Models for Sustainable Internet Regulation", TPRC 41: The 41st Research Conference on Communication, Information and Internet Policy, 15 August 2013

$<$ http://papers.ssrn.com/sol3/papers.cfm?abstract id $=2242$ $600>$ accessed 14 December 2013.

[156] Network effect, 2013. Wikipedia $<$ https://en.wikipedia.org/wiki/Network_effects $>$ accessed 4 December 2013.

[157] Noam, Eli, 2002. "The Effect of Deregulation on Market Concentration: an Analysis of the Telecom Act of 1996 and the Industry Meltdown", Colombia Institute for Tele-Information $<$ http://www.citi.columbia.edu/elinoam/articles/Effect of Deregulation_on_MarketConcentration.pdf $>$ accessed 3 
December 2013.

[158] Noam, Eli, 2012. "Media Concentration in America and the World", presentation at the $13^{\text {th }}$ Annual Conference: Civil Liberties and Competition Policy, 21 June 2012 $<$ http://www.antitrustinstitute.org/events/13th-annual-conf erence-civil-liberties-and-competition-policy $>$ accessed 10 February 2013.

[159] Noam, Eli, and The International Media Concentration Collaboration, 2016. Who Owns the World's Media?: Media Concentration and Ownership around the World, Oxford University Press.

[160] Burch, Sally, 2014. "Power and democracy on the Net", America Latina en movimiento, 11 April 2014 $<$ http://www.alainet.org/active/72917> accessed 12 April 2014.

[161] Meyer, David , 2014. "We should be worrying about Google's assimilation and consolidation, and here's why", Gigacom, 10 January 2014

$<$ http://gigaom.com/2014/01/10/we-should-be-worrying-ab out-googles-assimilation-and-consolidation-and-heres-why $>$ accessed 12 January 2014.

[162] Oltermann, Peter, 2014. "Google is building up a digital superstate, says German media boss", The Guardian, 16 April 2014

$<$ http://www.theguardian.com/technology/2014/apr/16/goo gle-building-digital-superstate-german-media-dopfner?CM $\mathrm{P}=$ twt_gu $>$ accessed 1 April 2014.

[163] The Hindu, 2013. "Who owns data on the cloud?", The Hindu, 15 December 2013

$<$ http://www.thehindu.com/todays-paper/tp-national/tp-kar nataka/who-owns-data-on-the-cloud/article5461569.ece> accessed 16 December 2013.

[164] Hamburger, Tom, and Gold, Matea, 2014. "Google, once disdainful of lobbying, now a master of Washington influence", The Washington Post, 13 April 2014 $<\mathrm{http}$ //www.washingtonpost.com/politics/how-google-is-t ransforming-power-and-politicsgoogle-once-disdainful-oflobbying-now-a-master-of-washington-influence/2014/04/ 12/51648b92-b4d3-11e3-8cb6-284052554d74 story.html? hpid=zl $>$ accessed 14 April 2014.

[165] APNIC, 2013. Contribution to WTPF regarding Draft Opinions 3 and 4 on IPv6 "Internet Addressing in the 2010s: IPv4 exhaustion and address transfers, and their impact on IPv6 deployment", Information document 12 for WTPF-13, ITU < http://www.itu.int/md/S13-WTPF13-INF-0012/en>.

[166] Huston, Geoff, 2013. "Addressing 2012 - Another One Bites the Dust", The ISP Column, January 2013 $<$ http://www.potaroo.net/ispcol/2013-01/2012.html> accessed 22 June 2013.

[167]ITU, 2013b. IPv4 and IPv6 Issues, Background paper for WTPF-13

$<$ http://www.itu.int/en/wtpf-13/Documents/backgrounderwtpf-13-ipv4-ipv6-en.pdf $>$.

[168] DeNardis, Laura, 2009. Protocol Politics: The Globalization of Internet Governance. MIT Press.

[169] Huston, Geoff, 2009. "Is the Transition to IPv6 a 'Market Failure?", The ISP Column, September 2009 $<$ http://www.potaroo.net/ispcol/2009-09/v6trans.html> accessed 22 June 2013.

[170] Hill, Richard, 2013c. International Public Policy Issues Concerning IPv4 Addresses: Should Governments Intervene to Correct a Standardization Failure?, contribution to the public consultation of the ITU Council Working Group on Internet-related public policy issues $<$ http://www.itu.int/en/council/Pages/display.aspx?ListIte $\mathrm{mID}=59>$ accessed 20 November 2013 .

[171] Budde, Paul, 2014. "Internet Governance Back in the Limelight”, CircleID, 6 April 2014 $<\mathrm{http}$ //www.circleid.com/posts/20140406_internet_gover nance back in the limelight $/>$ accessed 9 April 2014.

[172] Hundt, Reed et al., 2012. Toward a Single Global Digital Economy, Aspen Institute Idea Project $<\mathrm{http}$ //www.aspeninstitute.org/sites/default/files/content/u pload/Toward_a_Single_Global_Digital_Economy_Aspen _IDEA_Project_0.pdf $>$ accessed 6 March 2014.

[173] Ermert, Monika, 2013. "German Parliament Votes to Protect News Snippets from Republishing”, Intellectual Property Watch, 22 March 2013 $<$ http://www.ip-watch.org/2013/03/22/german-parliamentvotes-to-protect-news-snippets-from-republishing/> accessed 15 April 2013.

[174] European Newspaper Publishing Association, 2013. European Publishers Urge European Commission to Challenge Google Further, Press Release, 25 June 2013 $<$ http://www.enpa.be/en/news/press-release-european-publ ishers-urge-european-commission-to-challenge-google-furt her_98.aspx $>$ accessed 26 June 2013

[175] Jones, Gavin, 2013. "Italy eyes 'Google tax' to help fix public finances", Reuters, 4 November 2013 < http://www.reuters.com/article/2013/11/04/us-italy-internet -tax-idUSBRE9A30RL20131104> accessed 5 November 2013.

[176] Naughton, John, 2013. "Edward Snowden's not the story. The fate of the Internet is", The Guardian, 28 July 2013 $<$ http://www.theguardian.com/technology/2013/jul/28/edw ard-snowden-death-of-internet> accessed 31 July 2013.

[177] Morozov, Evgeny, 2013. "The Price of Hypocrisy", Frankfuter Allgemeine, 24 July 2013 $<$ http://www.faz.net/aktuell/feuilleton/debatten/ueberwach ung/information-consumerism-the-price-of-hypocrisy-122 92374.html $>$ accessed 31 July 2013.

[178] Richards, Neil M., 2013. "The Dangers of Surveillance", Harvard Law Review, 25 March 2013 $<$ http://papers.ssrn.com/sol3/papers.cfm?abstract_id=2239 412> accessed 11 December 2013.

[179] Harcourt, Bernard E., 2015. Exposed: Desire and Disobedience in the Digital Age, Harvard University Press.

[180] Peter, Ian et al. 2014. "NETmundial submission: Roadmap for the Further Evolution of the Internet Governance Ecosystem - institutional mechanisms", Best Bits $<$ http://bestbits.net/netmundial-roadmap/accessed 5 March 2014.

[181] Dourado, Eli, 2012. "Internet Security Without Law: How Service Providers Create Online Order", Working Paper, Mercatus Center, no. 12-19, June 2012 $<$ http://mercatus.org/sites/default/files/ISP_Dourado_WP1 
219.pdf $>$ accessed 10 November 2013.

[182] Kuerbis, Brendan, 2013. "A Blueprint For The Future Oversight of ICANN", Internet Governance Project, 16 October 2013

$<$ http://www.internetgovernance.org/2013/10/16/a-bluepri nt-for-the-future-oversight-of-icann/> accessed 30 October 2013.

[183] Kuerbis, Brendan, 2013a. "“A Contract With You", Internet Governance Projet, 5 November 2013 $<$ http://www.internetgovernance.org/2013/11/05/a-contract -with-you/> accessed 14 November 2014.

[184] Mueller, Milton, 2013d. "An Internet 'Free From Government Control': A Worthy Principle", Internet Governance Project, April 14, 2013 $<$ http://www.internetgovernance.org/2013/04/14/an-intern et-free-from-government-control-a-worthy-principle/> accessed 28 July 2013.

[185] O’Brien, Danny, 2014. “Human Rights Are Not Negotiable: Looking Back At Brazil's NETmundial”, Electronic Freedom Foundation, $25 \quad$ April 2014 $<$ https://www.eff.org/deeplinks/2014/04/netmundial> accessed 26 April 2014.

[186] Powles, Julia, 2014a. "Big business was the winner at NETmundial", Wired, 28 April 2014 $<$ http://www.wired.co.uk/news/archive/2014-04/28/interne t-diplomacy-netmundial $>$ accessed 28 April 2014.

[187] GIP team, "Why NETmundial mattered and what was achieved", Geneva Internet Platform, 24 April 2014 $<$ http://giplatform.org/resources/why-netmundial-mattered -and-what-was-achieved $>$ accessed 26 April 2014

[188] Ermert, Monika, 2014. "NETmundial Internet Governance Meeting Closes with Less Than 'Rough Consensus", Intellectual Property Watch, 25 April 2014 $<$ http://www.ip-watch.org/2014/04/25/netmundial-internet -governance-meeting-closes-with-less-than-rough-consens us/> accessed 26 April 2014.

[189] Nordenstreng, Kaarle and Schiller, Herbert, 1997. National Sovereignty and International Communication: A reader, Ablex Publishing Corporation.

[190] Cox, Ryan, 2014. "We have 18 months to find new governance for a single Internet, says ICANN", siliconAngle, 10 January 2014

$<$ http://siliconangle.com/blog/2014/01/10/icanns-fadi-cheh ade-says-we-have-18-months-to-find-new-governance-fora-single-internet-or-else/> accessed 13 January 2014.

[191] European Commission, 2014. Internet Policy and Governance: Europe's role in shaping the future of Internet Governance, Communication from the Commission to the European Parliament, the Council, the European Economic and Social Committee and the Committee of the Regions, $\operatorname{COM}(2014) 72 / 4$

$<$ http://ec.europa.eu/information_society/newsroom/cf/dae /document.cfm?doc_id=4453> accessed 16 February 2014.

[192] Strickling, Lawrence (2014). "Statement of Assistant Secretary Strickling on the European Commission Statement on Internet Governance", Press Release, 12 February 2014

$<$ http://www.ntia.doc.gov/press-release/2014/statement-ass istant-secretary-strickling-european-commission-statement -internet-g> accessed 16 February 2014.

[193] NTIA, 2014. "NTIA Announces Intention to Transition Key Internet Domain Name Functions", US National Telecommunications and Information Administration, Press Release, 14 March $2014<$ http://www.ntia.doc.gov/press-release/2014/ntia-announce s-intent-transition-key-internet-domain-name-functions> accessed 15 March 2014.

[194] Timberg, Craig, 2014. "U.S. to relinquish remaining control over the Internet", The Washington Post, 14 March $2014<$ http://www.washingtonpost.com/business/technology/us-to -relinquish-remaining-control-over-the-internet/2014/03/14 /0c7472d0-abb5-11e3-adbc-888c8010c799_print.html> accessed 15 March 2014.

[195] Powles, Julia, 2014. "US pledges to loosen grip on net. Don't be fooled", Wired, 18 March 2014 $<$ http://www.wired.co.uk/news/archive/2014-03/18/us-inte rnationalise-internet> accessed 18 March 2014.

[196] Myers, Jessica and Mershon, Erin, 2014. "Internet transition triggers GOP backlash", Politico, 15 March 2014 $<$ http://www.politico.com/story/2014/03/internet-transition -triggers-gop-backlash-104698.html $>$ accessed 17 March 2014.

[197] Berggruen, Nicolas, and Gardels, Nathan, 2013. Intelligent Governance for the $21^{\text {st }}$ Century: A Middle Way Between West and East, Polity.

[198] McCoy, Alfred, 2013. "Surveillance Blowback: The Making of the US Surveillance State, 1898-2020", Popular Resistance, 15 July 2013

$<$ http://www.popularresistance.org/surveillance-blowbackthe-making-of-the-us-surveillance-state-1898-2020/> accessed 30 August 2013.

[199] Internet Society et al., 2013. Montevideo Statement on the Future of Internet Cooperation, AFRINIC, ARIN, APNIC, IAB, ICANN, IETF, ISOC, LACNIC, RIPE NCC, W3C, 7 October 2013

$<\mathrm{http}$ //www.internetsociety.org/news/montevideo-stateme nt-future-internet-cooperation> accessed 20 October 2013.

[200] Editors, The Economist, 2010. "The future of the Internet: A virtual counter-revolution", The Economist, 2 September 2010<http://www.economist.com/node/16941635> accessed 25 February 2014.

[201] Lametti, David, 2012. "The Cloud: Boundless Digital Potential or Enclosure 3.0", working paper, 5 June 2012 $<$ https://papers.ssrn.com/sol3/papers.cfm?abstract_id=207 7742> accessed 16 March 2014.

[202] CITI, 2013. "Is There A Third Way For The Internet: Neither The US Nor The UN But Independence?", Columbia Institute for Tele-Information, e-conference, 12 November $2013<$ http://isoc-ny.org/p2/6092> accessed 18 November 2013.

[203] Taylor, Matthew, Hopkins, Nick and Kiss, Jemima, 2013. "NSA surveillance may cause breakup of internet, experts warn", The Guardian, 1 November 2013 $<$ http://www.theguardian.com/world/2013/nov/01/nsa-surv eillance-cause-internet-breakup-edward-snowden $>$ accessed 4 November 2013.

[204] Internet Society, 2012. "The Internet and the Public 
Switched Telephone Network: Disparities, Differences and Distinctions", 1 June 2012

$<$ http://www.internetsociety.org/sites/default/files/The $\% 20$ Internet $\% 20$ and $\% 20$ the $\% 20$ Public $\% 20$ Switched $\% 20$ Telep hone $\% 20$ Network.pdf $>$ accessed 12 August 2013.

[205] Mueller, Milton, 2017, Will the Internet Fragment: Sovereignty, Globalization, and Cyberspace, polity.

[206] Ibrahim, H., 2012, "Internet Technical community perspective on the proposed amendments to the ITRs", AFRINIC, 8 May 2012

$<$ http://www.internetsociety.org/sites/default/files/Internet \%20Technical\%20Community\%20ITRs.pdf> accessed 12 August 2013.

[207] Huston, Geoff, 2013a. An End-to-End View of Telecommunications Policy Frameworks,. Information document 1 for WTPF-13, ITU

$<$ http://www.itu.int/md/S13-WTPF13IEG3-INF-0001/en>.

[208] Toll-free telephone number. 2013. Wikipedia $<$ http://en.wikipedia.org/wiki/Toll-free_telephone_number $>$ accessed 21 November 2013.

[209] DNS, 2013. Wikipedia

$<$ http://en.wikipedia.org/wiki/Dns\#Operation>accessed 21 November 2013.

[210]Local Number Portability, 2013. Wikipedia $<$ http://en.wikipedia.org/wiki/Local_number_portability $>$ accessed 21 November 2013.

[211]Mobile Number Portability, 2013. Wikipedia $<$ http://en.wikipedia.org/wiki/Mobile_number_portability> accessed 21 November 2013.

[212] Pouzin, Louis, 2014. "Internet governance, what next?", submission to NETMundial meeting, 23-24 April $2014<$ $\mathrm{http} / / /$ content.netmundial.br/contribution/internet-governan ce-what-next/129> accessed 15 March 2014.

[213] Chandar, Anupam and Le, Uyen, 2014. "Breaking the Web: Data Localization vs. the Global Internet", UC Davis Legal Studies Research Paper No. 2014-1, 12 March 2014 $<$ http://papers.ssrn.com/sol3/papers.cfm?abstract id $=2407$ $858>$ accessed 15 March 2014.

[214] Hattem, Julian, 2014. "Google chief on NSA: 'We're going to end up breaking the Internet'", The Hill, 8 October 2014 $<$ http://thehill.com/policy/technology/220176-google-head -without-reform-nsa-will-break-the-internet> accessed 17 October 2014.

[215] Negro, Gianluigi 2013. “Chinese Internet Governance-Some Domestic and Foreign Issues", in Weber, R. H., Radu, R., and Chenou, J.-M. (eds). The evolution of global Internet policy: new principles and forms of governance in the making?, Schulthess/Springer.

[216] Deibert, Roland J. et al. (eds), 2008. Access Denied: The Practice and Policy of Global Internet Filtering, MIT Press.

[217] Deibert, Roland J. et al. (eds), 2010. Access Controlled: The Shaping of Power, Rights, and Rule in Cyberspace, MIT Press.

[218] Musil, Steven, 2013. "Iran develops software to control social networks". CNET, 6 January 2013 $<$ http://news.cnet.com/8301-1023_3-57562295-93/iran-de velops-software-to-control-access-to-social-networks/> accessed 15 June 2013.

[219] Simonite, Tom, 2013. "Reading the Tea Leaves of Censorship", MIT Technology Review, vol. 115, no. 4, July/August 2013, p. 20.

[220] Karachi Voice, 2013. "Will Pakistan have its own YouTube?", The Karachi Voice, 11 December 2013 $<$ http://www.thekarachivoice.net/66/post/2013/12/will-pak istan-have-its-own-youtube.html $>$ accessed 13 December 2013.

[221] Robertson, Jordan, 2013. "A New Twist in International Relations: The Corporate 'Keep My Data Out of the US' Clause", Bloomberg, 24 December 2013 $<$ http://www.bloomberg.com/news/2013-12-24/a-new-twis t-in-international-relations-the-corporate-keep-my-data-out -of-the-u-s-clause.html> accessed 27 December 2013.

[222] Toor, Amar, 2014. "Cutting the cord: Brazil's bold plan to combat the NSA", The Verge, 9 May 2017 $<$ http://www.theverge.com/2013/9/25/4769534/brazil-to-b uild-internet-cable-to-avoid-us-nsa-spying $>$ accessed 10 February 2014

[223] Emmott, Robin and Guarascio, Francesco, 2014. "Brazil presses EU for undersea cable to skirt U.S. links", Reuters, 24 February 2014

$<$ http://uk.reuters.com/article/2014/02/24/uk-eu-brazil-idU KBREA1N0PG20140224> accessed 25 February 2014

[224] Estes, Adam Clark, 2014. "Brazil is Keeping Its Promise to Avoid the U.S. Internet", GIZMODO, 30 October 2014 $<$ http://gizmodo.com/brazils-keeping-its-promise-to-discon nect-from-the-u-s-1652771021>.

[225] Thomas, Thomas, 2014. "National Security Council proposes 3-pronged plan to protect Internet Users, The Hindu Business Line, 13 February 2014 $<$ http://www.thehindubusinessline.com/features/smartbuy/ national-security-council-proposes-3pronged-plan-to-prote ct-internet-users/article5685794.ece> accessed 21 February 2014.

[226] Swiss Government, 2014. "Le Conseil fédéral adopte des mesures visant à protéger les infrastructures de la Confédération en matière de TIC, 5 February 2014" $<$ http://www.admin.ch/aktuell/00089/index.html?lang=fr\& msg-id=51911 $>$ accessed 6 February 2014 .

[227] Paterson, Tony, 2014. "Surveillance revelations: Angela Merkel proposes European network to beat NSA and GCHQ spying", The Independent, 16 February 2014 $<\mathrm{http}$ //www.independent.co.uk/news/world/europe/angela -merkel-proposes-european-network-to-beat-nsa-spying-91 32388.html $>$ accessed 18 February 2014.

[228] MacAskill, Ewen, 2014. "Putin calls internet a 'CIA project' renewing fears of web breakup", The Guardian, 24 April 2014

$<$ http://www.theguardian.com/world/2014/apr/24/vladimir -putin-web-breakup-internet-cia> accessed 25 April 2014.

[229] Schiller, Dan, 2014c. "We've got our eye on you", Le Monde diplomatique, November 2014 $<$ http://mondediplo.com/2014/11/02dsnowden>.

[230] Miller, Claire Cain, 2014. "Revelations of N.S.A. Spying Cost U.S. Tech Companies", New York Times, 21 March 2014 
$<$ http://www.nytimes.com/2014/03/22/business/fallout-fro m-snowden-hurting-bottom-line-of-tech-companies.html> accessed 24 March 2014.

[231] Levy, Steven, 2014. "How the NSA Almost Killed the Internet", Wired, 7 January 2014

$<$ http://www.wired.com/threatlevel/2014/01/how-the-us-al most-killed-the-internet/all/\#x> accessed 9 January 2014.

[232] Internet Society, 2014. "Internet Society Urges President Obama to Effect 'Immediate and Meaningful' Changes to U. S. Government Surveillance Practices", 15 January $2014<$ http://www.internetsociety.org/news/internet-society-urges -president-obama-effect- $\% \mathrm{E} 2 \% 80 \% 98$ immediate-and-mea ningful $\% \mathrm{E} 2 \% 80 \% 99$-changes-us-government> accessed 16 January 2014.

[233] Community Informatics Research Network, 2013. An Internet for the Common Good

$<$ http://cirn.wikispaces.com/An+Internet+for+the+Commo $\mathrm{n}+$ Good+-+Engagement, + Empowerment, + and + Justice + for + All $>$ accessed 23 December 2013.

[234] Timberg, Craig, Gellman, Barton and Soltani, Ashkan, 2013. "Microsoft, suspecting NSA spying, to ramp up efforts to encrypt its Internet traffic", The Washington Post, 27 November 2013

$<$ http://www.washingtonpost.com/business/technology/mi crosoft-suspecting-nsa-spying-to-ramp-up-efforts-to-encry pt-its-internet-traffic/2013/11/26/44236b48-56a9-11e3-830 4-caf30787c0a9 story.html> accessed 6 December 2013.

[235] Gapper, John, 2013. "Silicon Valley must keep the spies out of its honey trap", Financial Times, 11 December 2013 $<$ http://www.ft.com/intl/cms/s/0/1d685b5e-619d-11e3-b7f 1-00144feabdc0.html\#axzz2o80UaNaS> accessed 21 December 2013.

[236] Astruc, Maeli, 2014. "Seminar Shows Continued Divergence Among Nations On Regulating Internet", Intellectual Property Watch, 14 February 2014 $<$ http://www.ip-watch.org/2014/02/14/seminar-shows-cont inuing-divergence-among-nations-on-regulating-internet/> accessed 16 February 2014.

[237] Hill, Richard, 2018. "Analysis of the Working Group on Enhanced Cooperation on Public Policy Issues Pertaining to the Internet", Intellectual Property Watch, 5 February 2018 $<$ https://www.ip-watch.org/2018/02/05/analysis-working-g roup-enhanced-cooperation-public-policy-issues-pertaining -internet/> accessed 13 March 2018.

[238] South Africa, 2013. "Proposed ICT Review Policy Framing Paper", Government Gazette, 24 April 2013, no. 36408, p. 3, notice 429 of 2013

$<$ http://www.info.gov.za/view/DownloadFileAction?id=18 8939> accessed 9 December 2013.

[239] Kurbalija, Jovan, 2013. "International inviolability for the root zone?", Diplo, 9 December 2013 $<$ http://www.diplomacy.edu/blog/international-inviolabilit y-root-zone > accessed 9 December 2013.

[240] Kampmark, Binoy, 2013. “A Digital Bill of Rights: Petitioning the Surveillance State", Counterpunch, 12 December 2013

$<$ http://www.counterpunch.org/2013/12/12/a-digital-bill-of -rights/> accessed 13 December 2013.

[241] Levi, Josh, and Avila, Renata, 2013. "The Decentralized Web", Freepress, 11 December 2013

$<$ http://www.freepress.net/blog/2013/12/11/decentralizedweb $>$ accessed 13 December 2013.

[242] Talbot, David, 2013. "Bruce Schneier: NSA Syping Is Making Us Less Safe", Technology Review, 23 September 2013

$<$ http://www.technologyreview.com/news/519336/bruce-s chneier-nsa-spying-is-making-us-less-safe/> accessed 23 January 2014.

[243] Moglen, Eben, 2013a. Snowden and the Future: Part II; Oh Freedom, lecture at Columbia Law School, 9 October 2013 $<$ http://snowdenandthefuture.info/snowdenandthefuture-oh freedom.pdf $>$ accessed 15 December 2013.

[244] ITU, 2014. "Lost Something on the Internet? Never Again With New Digital Object (DO) Architecture", itublog, 6 January 2014

$<$ http://itu4u.wordpress.com/2014/01/06/lost-something-on -the-internet-never-again-with-new-digital-object-do-archit ecture/ > accessed 11 January 2014.

[245] Wimmer, Kurt, 2012. "The Proper Standard for Constitutional Protection of Internet Search Practices", paper presented at the $13^{\text {th }}$ Annual Conference: Civil Liberties and Competition Policy, 21 June 2012 http://www.antitrustinstitute.org/events/13th-annual-confer ence-civil-liberties-and-competition-policy; the paper is at $<$

http://www.mediacompolicy.org/wp-content/uploads/sites/ 296/2012/06/First-Amendment-Issues-in-Search-and-Antit rust-6-2.pdf $>$ accessed 6 April 2014.

[246] Eggers, David, 2013. The Circle, Knopf

[247] Rioux, Michèle with Adam, Nicolas and Company Pérez, Biel, 2013. "Competing International Trajectories for Global Regulation-Internet in a Fragmented World", in Weber, R. H., Radu, R., and Chenou, J.-M. (eds), The evolution of global Internet policy: new principles and forms of governance in the making?, Schulthess/Springer.

[248] Canazza, Mario (2016). "The Internet as a Global Public Good and the Role of Governments and Multilateral Organizations in Internet Governance", unpublished Master's Degree thesis, University of Columbia $<$ http://www.apig.ch/Canazza\%20thesis\%20Internet\%20as \%20public\%20good.pdf $>$ accessed 10 January 2018.

*The author wishes to thank the anonymous reviewers for their helpful comments. 